\title{
Facile Synthesis of Metal Doped Graphite Carbon Nitride for Photocatalytic Degradation of Tetracycline Under Visible Light Irradiation
}

yin zhao

Hunan University

hong qin

Hunan University

Qianlan luo

Changsha Liuyang Eco-environmental Monitoring Station

ziwei wang

Hunan University

han wang

Hunan University

zixuan wang

Hunan University

yangzhuo he

Hunan University

Quyang Tian

Hunan University

Changlin Wang

Hunan University

Piao Xu ( $\nabla$ piaoxu@hnu.edu.cn)

Hunan University

\section{Research Article}

Keywords: Carbon nitride, Metal-doping, Tetracycline, Photodegradation

Posted Date: September 7th, 2021

DOl: https://doi.org/10.21203/rs.3.rs-833246/v1

License: (c) (1) This work is licensed under a Creative Commons Attribution 4.0 International License.

Read Full License 


\section{Abstract}

Using semiconductor photocatalysts for antibiotic contaminants degradation under visible light has become a hot topic in recent years. Herein, a novel cadmium doped graphite phase carbon nitride (Cd/g$\mathrm{C}_{3} \mathrm{~N}_{4}$ ) photocatalyst was successfully constructed via $60^{\circ} \mathrm{C}$ oil bath method to degrade tetracycline. Experimental and characterization results revealed that cadmium was well doped at g- $\mathrm{C}_{3} \mathrm{~N}_{4}$ surface and exhibited high intercontact with g- $\mathrm{C}_{3} \mathrm{~N}_{4}$. Meanwhile, $\mathrm{Cd} / \mathrm{g}-\mathrm{C}_{3} \mathrm{~N}_{4}$ presented excellent electrical conductivity and inhibited the recombination of electron-hole pairs. The introduction of cadmium significantly improved the photocatalytic activity and the degradation efficiency of $10 \mathrm{Cd} / \mathrm{g}-\mathrm{C}_{3} \mathrm{~N}_{4}$ reached to $89.09 \%$, which was exceeded 2.0 times than pure g- $\mathrm{C}_{3} \mathrm{~N}_{4}(43.99 \%)$. Additionally, the quenching experiments and electron spin-resonance tests exhibited holes $\left(\mathrm{h}^{+}\right)$, hydroxyl radicals $(\cdot \mathrm{OH})$ and superoxide radicals $\left(\cdot \mathrm{O}_{2}{ }^{-}\right)$ were dominated active species in TC degradation. Furthermore, the effects of various conditions on the reaction process, such as different $\mathrm{pH}$, initial TC concentrations and catalyst dosage, were also researched. This work gives a reasonable point to synthesize high-efficiency and economic photocatalysts.

\section{Introduction}

For the past few years, researchers have been seeking suitable ways to solve the overwhelming environmental problems, especially caused by the continuous increase of population and energyintensive industry (Abbott 2010, McCauley \&Stephens 2012, Wang \&Yang 2016). Photocatalysis, as an environmental-friendly process, has become the significant method applied in energy and environmental remediation field (Ge et al. 2011, Liu et al. 2016, Wang et al. 2008, Zhu et al. 2017). Undoubtedly, the most important tasks in photocatalysis research are designing high-efficient, stable and low-cost photocatalysts, which should include excellent light absorption capacity, non-toxic, narrow band gap, controllable morphology and good redox ability (Xiang et al. 2012). Recently, metallic oxides, metallic nitrides, metallic sulfides were developed as excellent photocatalytic material to remove organic pollutants (Chan et al. 2017, Shi et al. 2018, Song et al. 2019, Wang et al. 2018b, Xiao \&Jiang 2017, Xu et al. 2019). Whereas, some obvious defects have hindered their further application. In comparison, more recently discovered carbon nitride in several covalent $\mathrm{CN}$ allotropes is considered as one of the most promising photocatalysts than metallic photocatalysts (Dong et al. 2012, Samanta et al. 2014, Wang et al. 2008).

Among the five phases (alpha, beta, cubic, quasi-cubic and graphite phase) of carbon nitride, graphite phase carbon nitride $\left(\mathrm{g}-\mathrm{C}_{3} \mathrm{~N}_{4}\right)$ was widely used in organic pollutants degradation, owing to its high physicochemical stability, adjustable electronic structure and molecular tunability (Butchosa et al. 2014, Fan et al. 2016, Liu et al. 2015, Samanta et al. 2014). Particularly, g- $\mathrm{C}_{3} \mathrm{~N}_{4}$, as a metal-free and environmentally benign conjugated catalyst (Lu et al. 2015, Zhou et al. 2013), possesses narrow diffusion length (Yan et al. 2009a), suitable specific surface area and appropriate band gap for absorbing blue light (Chai et al. 2012, Chen et al. 2020, Wang et al. 2020a, Wang et al. 2019, Wang et al. 2020b). 
However, the disadvantages of $\mathrm{g}-\mathrm{C}_{3} \mathrm{~N}_{4}$ cannot be ignored, such as insufficient light absorption (Li et al. 2009a), and rapid recombination rate of photo-generated carriers (Chang et al. 2018, Zhang \&Xia 2011).

Several strategies, including chemical doping, morphological control, electronic structural design and defects engineering have been explored to overcome inherent shortcomings of g- $\mathrm{C}_{3} \mathrm{~N}_{4}$ and subsequently enhance the photocatalytic performance (Gao et al., Katsumata et al. 2014, Ou et al. 2015, Qi et al. 2018). Among these strategies, metal elements doping of $\mathrm{g}-\mathrm{C}_{3} \mathrm{~N}_{4}$ is regarded as a fungible and feasible method to improve the photocatalytic performance. And the reported researches have been commonly exhibited the advantages of metal elements doping g- $\mathrm{C}_{3} \mathrm{~N}_{4}$, first of all, metal dopants can generate lone electron pairs in $\mathrm{g}-\mathrm{C}_{3} \mathrm{~N}_{4}$ as it interacts with the cations, thus enhancing its ability to capture electrons (Gao et al. 2013, Ong et al. 2016, Wang et al. 2009a). In addition, metal doping can effectively adjust the morphology and crystal phase of $\mathrm{g}-\mathrm{C}_{3} \mathrm{~N}_{4}$, thus introducing oxygen vacancies or constructing heterogeneous structures to enhance the photocatalytic activity of the catalyst. Meanwhile, metal doping can extend visible light absorption range, improve charge transfer efficiency, and enhance redox capacity (Fan et al. 2019, Huang et al. 2019, Jun et al. 2013, Liu et al. 2012, Samanta et al. 2014, Schwinghammer et al. 2014, Wang et al. 2018b, Zhao et al. 2014).

In addition, calcination is the most used method to obtain metal doped g- $\mathrm{C}_{3} \mathrm{~N}_{4}$ (Thaweesak et al. 2017, Yan et al. 2010, Zhu et al. 2017), different forms of $\mathrm{g}-\mathrm{C}_{3} \mathrm{~N}_{4}$ were synthesized through calcination approach with different parameters (Yu \&Wang 2015, Yuan et al. 2014), like nanotube (Gao et al. 2012), hollow sphere (Jun et al. 2013), nanofiber (Tahir et al. 2013), nanowire (Zhang et al. 2016c), nanoribbon (Zhao et al. 2014), nanosheet (Schwinghammer et al. 2014).

In this paper, different proportions of cadmium were introduced into porous $\mathrm{g}-\mathrm{C}_{3} \mathrm{~N}_{4}$ photocatalyst to degraded TC via oil bath and calcination method. To the best of our knowledge, there is rarely reported of cadmium doped $\mathrm{g}-\mathrm{C}_{3} \mathrm{~N}_{4}$ for photocatalytic degradation. The experimental results of photodegrading $\mathrm{TC}$ under visible light irradiation demonstrated that $\mathrm{Cd} / \mathrm{g}-\mathrm{C}_{3} \mathrm{~N}_{4}$ possessed the higher photocatalytic performance in comparison with that of pure g- $\mathrm{C}_{3} \mathrm{~N}_{4}$. This study offers an innovative viewpoint for $\mathrm{g}-\mathrm{C}_{3} \mathrm{~N}_{4}$ modification for further chemistry doped and elaborates the mechanism of cadmium doping for photoactivity improvement in detail.

\section{Experiment Part \\ 2.1. Chemicals}

All the chemicals were of analytical grade. Cadmium chloride $\left(\mathrm{CdCl}_{2}\right)$, melamine, tetracycline (TC), ethylenediaminetetraacetic acid disodium salt (EDTA-2Na), anhydrous ethanol, isopropanol (IPA), 4hydroxy-2,2,6,6-tetramethylpiperidinyloxy (TEMPO), deionized water $\left(\mathrm{H}_{2} \mathrm{O}\right)$, were employed without further purification.

\subsection{Synthesis of $\mathrm{g}-\mathrm{C}_{3} \mathrm{~N}_{4}$}


g- $\mathrm{C}_{3} \mathrm{~N}_{4}$ was prepared via traditional calcination method and the specific steps were as follows (Wang et al. 2021): Weighing $10 \mathrm{~g}$ melamine into a porcelain alumina crucible, covered with tin foil, then the crucible was placed into muff furnace with a heating rate of $10^{\circ} \mathrm{C} / \mathrm{min}$ and kept at $550^{\circ} \mathrm{C}$ for $3 \mathrm{~h}$. After the porcelain alumina crucible was cooled down to room temperature, the obtained g- $\mathrm{C}_{3} \mathrm{~N}_{4}$ powder was grounded and collected for further use.

\subsection{Synthesis of $\mathrm{Cd} / \mathrm{g}-\mathrm{C}_{3} \mathrm{~N}_{4}$}

$\mathrm{Cd} / \mathrm{g}-\mathrm{C}_{3} \mathrm{~N}_{4}$ was prepared through the thermal polymerization of melamine in the presence of $\mathrm{CdCl}_{2} .1 .0 \mathrm{~g}$ $\mathrm{g}-\mathrm{C}_{3} \mathrm{~N}_{4}$ sample was taken and dissolved in $20 \mathrm{~mL}$ of ethanol/ $\mathrm{H}_{2} \mathrm{O}$ solution $(15 / 5, \mathrm{vol} / \mathrm{vol})$, then put different amounts of $\mathrm{CdCl}_{2}$ into the solution. After ultrasound for half an hour, the solvent evaporated in an oil bath under magnetic agitation at $60^{\circ} \mathrm{C}$. The remaining solids were placed in a petri dish, covered with plastic wrap and dried in vacuum drying oven at $60^{\circ} \mathrm{C}$ for $24 \mathrm{~h}$, when cooled to room temperature, the obtained samples were poured into a mortar to thoroughly ground. Then the samples were placed into muff furnace with a heating rate of $5^{\circ} \mathrm{C} / \mathrm{min}$, kept at $550^{\circ} \mathrm{C}$ for $3 \mathrm{~h}$. When the product was static cooled, $\mathrm{Cd} / \mathrm{g}-\mathrm{C}_{3} \mathrm{~N}_{4}$ composite photocatalysts with different cadmium contents were prepared. The product was ground into powder and marked as $X \mathrm{Cd} / \mathrm{g}-\mathrm{C}_{3} \mathrm{~N}_{4},(X=3,5,7,10,15,20,30)$ according to different mass ratios.

\subsection{Characterization}

X-ray diffraction (XRD) of $\mathrm{Cd} / \mathrm{g}-\mathrm{C}_{3} \mathrm{~N}_{4}$ was obtained by D8 advance via Cu-Ka radiation. The scan ranges of $2 \theta$ extended from $10^{\circ}$ to $80^{\circ}$ with a scan speed of $8^{\circ} / \mathrm{min}$. The morphological structure was obtained on JSM-7800F scanning electron microscopy (SEM). Escalab 250Xi spectrometer via Al Ka X-ray source was used to measure X-ray photoelectron spectroscopy (XPS). The morphologies of the catalyst were observed through Jeol 2100F transmission electron microscopy (TEM). The photoluminescence spectra $(\mathrm{PL})$ spectra were investigated by Fluoromax-4 spectrofluorometer at $380 \mathrm{~nm}$ excitation wavelength. Fourier transform infrared spectroscopy (FT-IR) was measured by Bruker spectrometer, with the wavenumber ranging from 500 to $4000 \mathrm{~cm}^{-1}$. Ultraviolet- visible diffuse reflectance absorption spectroscopy (UV-Vis DRS) was performed on Cary 300 UV-Vis spectrophotometer scanning from 200 $800 \mathrm{~nm}$. The Brunauer-Emmett-Teller (BET) surface area was carried out by Micromeritics ASAP2460. Electrochemical impedance spectroscopy (ESR) was analyzed by Bruker a300. The total organic carbon (TOC) was tested via Analytikjena multi N/C 2100. The chemical element compositions were also analyzed by the energy dispersive spectroscopy (EDS) mapping images captured on a Zeiss Sigma 300 atomic resolution analytical microscope.

\subsection{Photocatalytic process}

A $300 \mathrm{~W}$ Xenon lamp with $420 \mathrm{~nm}$ pass filter in the laboratory was employed to simulate sunlight for catalytic process. Typically, $0.04 \mathrm{~g}$ catalyst was weighed and put in a $100 \mathrm{~mL}$ beaker. Then $50 \mathrm{~mL}$ TC solution at $20 \mathrm{mg} / \mathrm{L}$ was poured in the beaker and put it on a blender and set the rotate speed at 450 $\mathrm{rpm} / \mathrm{s}$ for photocatalysis studies. In order to eliminated the effect of adsorption, we placed the mixture 
solutions in the dark and stirred for 0.5 hour until the adsorption-desorption equilibrium. During the light source was added, TC suspension was collected every $10 \mathrm{~min}$ with a syringe and filtered with $0.22 \mu \mathrm{m}$ membrane. The samples were taken 6 times in an hour. Then the concentration of suspension was tested by UV-Vis spectrophotometer with wavelength at $357 \mathrm{~nm}$.

\subsection{Photoelectrochemical process}

The photoelectrochemical test of catalyst was obtained from the instrument of CHI0-660D workstation. The PEC performance of the $\mathrm{g}-\mathrm{C}_{3} \mathrm{~N}_{4}$ and $\mathrm{Cd} / \mathrm{g}-\mathrm{C}_{3} \mathrm{~N}_{4}$ electrodes was evaluated using a normal threeelectrode system with $0.2 \mathrm{M} \mathrm{Na}_{2} \mathrm{SO}_{4}$ solution under illumination or in the dark. In the three electrodes system, Ag/ AgCl electrode was reference electrode, Pt electrode was counter electrode and working electrode was $150 \mu \mathrm{L}$ diluted catalyst adhered to fluorine-doped tin oxide (FTO). The load operation process was depicted as follows: FTO was firstly ultrasonic cleaned in ethanol, acetone and deionized water for three times, respectively. Secondly, $10 \mathrm{mg}$ catalyst was uniformly imported into $150 \mathrm{uL}$ naphthol for ultrasonic oscillation. Finally, $100 \mu \mathrm{L}$ suspension was evenly dropped onto FTO and dried at $120^{\circ} \mathrm{C}$. In the three-electrode system, a $300 \mathrm{~W}$ Xenon lamp with $420 \mathrm{~nm}$ pass filter in the laboratory was used as light source, then $0.2 \mathrm{M} \mathrm{Na}_{2} \mathrm{SO}_{4}$ aqueous solution was poured into the system until liquid passed through the catalyst as electrolyte.

\section{Results And Discussion}

\subsection{Structure and morphology}

Structure and crystalline phase of pure $\mathrm{g}-\mathrm{C}_{3} \mathrm{~N}_{4}$ and $\mathrm{Cd} / \mathrm{g}-\mathrm{C}_{3} \mathrm{~N}_{4}$ were analyzed by XRD. Figure $1 \mathrm{a}$ showed two diffraction peaks appear at vicinity of $12.9^{\circ}(100)$ and $27.5^{\circ}(002)$, which were labeled as the typical graphitic carbon nitride in pure g- $\mathrm{C}_{3} \mathrm{~N}_{4}$ and in good agreement with the standard XRD pattern of graphitic carbon nitride (JCPDS 87-1526). The in-planar tri-s-triazine structural ordering of the conjugated aromatic system was confirmed by the peak at $12.9^{\circ}$ and the distance between the in-plane layers was about 0.69 $\mathrm{nm}$. The peak at $27.5^{\circ}$ represented the inter-planar periodic lamellar ordering of typical graphite-like carbon nitride, and the distance between the inter-planar layers was about $0.33 \mathrm{~nm}$, calculated according to Bragg's Law (Lu et al. 2015, Zou et al. 2019). However, the intensities of both two peaks of Cd/g- $\mathrm{C}_{3} \mathrm{~N}_{4}$ were significantly decreased with the increasing cadmium doping, and the (100) peak almost disappeared, indicating that the introduction of the $\mathrm{Cd}$ affected the chemical structure and reduced hydrogen bond effect in the intralayer of $\mathrm{g}-\mathrm{C}_{3} \mathrm{~N}_{4}$, thus decreasing the distance between the inter-planar layers and loose packing of layers in $\mathrm{g}-\mathrm{C}_{3} \mathrm{~N}_{4}$ (Thaweesak et al. 2017, Yu et al. 2016). It is worth noting that the (002) peak displayed a slight shift to higher angles in $\mathrm{Cd} / \mathrm{g}-\mathrm{C}_{3} \mathrm{~N}_{4}$ samples, suggesting the decrease of interlayer distance in $\mathrm{Cd} / \mathrm{g}-\mathrm{C}_{3} \mathrm{~N}_{4}$. Apparently, there were no peak of cadmium in any form in $\mathrm{Cd} / \mathrm{g}-\mathrm{C}_{3} \mathrm{~N}_{4}$ composites compared with pure $\mathrm{g}-\mathrm{C}_{3} \mathrm{~N}_{4}$, which was due to the small content and high dispersion in solution (Jia et al. 2019, Wang et al. 2020b). 
The possible functional groups in the $\mathrm{g}-\mathrm{C}_{3} \mathrm{~N}_{4}$ and $\mathrm{Cd} / \mathrm{g}-\mathrm{C}_{3} \mathrm{~N}_{4}$ were determined by FT-IR spectroscopy. As illustrated in Fig. $1 \mathrm{~b}$, the $\mathrm{Cd} / \mathrm{g}-\mathrm{C}_{3} \mathrm{~N}_{4}$ and g- $\mathrm{C}_{3} \mathrm{~N}_{4}$ exhibited almost similar FT-IR features, indicating the primary framework of $\mathrm{g}-\mathrm{C}_{3} \mathrm{~N}_{4}$ well preserved after $\mathrm{Cd}$ doping. The peak at $809 \mathrm{~cm}^{-1}$ was assigned to the typical out-of-plane bending vibration of tri-s-triazine-based structure (Liu et al. 2020), which verified the presence of triazine units (Yan et al. 2009b) and was consistent with previous findings (Wang et al. 2018a). Four characteristic peaks were found in the region of $1200-1600 \mathrm{~cm}^{-1}$, which appeared at 1245 , 1327,1412 and $1573 \mathrm{~cm}^{-1}$, respectively, indicating that the aromatic $\mathrm{C}-\mathrm{N}$ heterocycle $\left(\mathrm{C}_{6} \mathrm{~N}_{7}\right)$ had a distinctive stretching mode (Park et al. 2011). In addition, the O-H bending vibration was observed in all samples at $1630 \mathrm{~cm}^{-1}$ (Sobhana S S et al. 2011). Specifically, the peak at about $1645 \mathrm{~cm}^{-1}$ were the stretching vibration of typical $\mathrm{C}=\mathrm{N}$ units. The characteristic band at $2173 \mathrm{~cm}^{-1}$ corresponded to terminal cyano groups $(C \equiv N)$ (Yang et al. 2013). The wide region from 3000 to $3500 \mathrm{~cm}^{-1}$ were ascribed to the stretching mode of the $\mathrm{N}-\mathrm{H}$ in aromatic groups and $\mathrm{O}-\mathrm{H}$ stretching vibrations, which may be due to partial hydrogenation of exposed nitrogen and the adsorption of water molecules on the surface of the catalyst (Tonda et al. 2014, Wang et al. 2018a, Yan et al. 2016). The spectra of $\mathrm{Cd} / \mathrm{g}-\mathrm{C}_{3} \mathrm{~N}_{4}$ were basically as same as the pure $\mathrm{g}-\mathrm{C}_{3} \mathrm{~N}_{4}$, which confirmed that Cd doping did not change the functional group of $\mathrm{g}-\mathrm{C}_{3} \mathrm{~N}_{4}$.

The morphology and microstructure of $\mathrm{g}-\mathrm{C}_{3} \mathrm{~N}_{4}$ and $\mathrm{Cd} / \mathrm{g}-\mathrm{C}_{3} \mathrm{~N}_{4}$ were examined by SEM, and the image of g- $\mathrm{C}_{3} \mathrm{~N}_{4}$ without pre-treatment with $\mathrm{CdCl}_{2}$ were presented in Fig. 2a and Fig. 2b, which displayed an aggregated, thick irregular platelets and scattered crystals particle structure stacking with bulky nanosheets. The image revealed the pure g- $\mathrm{C}_{3} \mathrm{~N}_{4}$ was consists of randomly folded and stacked tri-striazine layers, which were piled up in an irregular manner to formed a porous structure (Narkbuakaew \&Sujaridworakun 2020). After the Cd doping, great difference could be seen in Fig. $2 \mathrm{c}$ and Fig. $2 \mathrm{~d}, \mathrm{Cd} / \mathrm{g}$ $\mathrm{C}_{3} \mathrm{~N}_{4}$ was composed of layer structure with some uniformly smaller particles on the surface. The thickness of the layer was thinner after employment of $\mathrm{CdCl}_{2}$, revealing a certain degree of exfoliation of the aggregated thick nanosheets. Additionally, the porosity of the $10 \mathrm{Cd} / \mathrm{g}-\mathrm{C}_{3} \mathrm{~N}_{4}$ was obviously increased, which might be related to the produce of light layer cracks during crystal growth process and evaporation of chlorine gas during heating process. Consequently, the increased pores could provide more reaction active sites, thus enhancing the photocatalytic activity.

The detailed microstructure features and subtle morphologies of materials were further surveyed by TEM. As depicted in Fig. 3a and Fig. 3b, it could be clearly seen that the structure of pure g- $\mathrm{C}_{3} \mathrm{~N}_{4}$ was transparent or non-transparent nanosheets because of ultrathin thickness or the overlap of a few nanosheets. Moreover, we could clearly observe a piece of a typical silk nanosheet with smooth external surface and flat layer structures of the obtained g- $\mathrm{C}_{3} \mathrm{~N}_{4}$, which manifested that the graphene-like layers were uniformly distributed and like randomly oriented. Obviously, randomly folded and stacked layer were easily piled up in an irregular manner to an agglomerate. As shown in Fig. $3 \mathrm{c}$ and Fig. 3d, the $10 \mathrm{Cd} / \mathrm{g}$ $\mathrm{C}_{3} \mathrm{~N}_{4}$ exhibited a multilayered nanosheets structure and laminated crystallizes with abundant microporous. Further, the cadmium nanoparticles were well doped at $\mathrm{g}-\mathrm{C}_{3} \mathrm{~N}_{4}$ surface and exhibited high intercontact with $\mathrm{g}-\mathrm{C}_{3} \mathrm{~N}_{4}$, there were many small holes in the nanosheet, which was beneficial for 
increasing the specific surface area significantly. Fig. S1 and Table S1 illustrated the weight ratio of Cd/g$\mathrm{C}_{3} \mathrm{~N}_{4}$ composites, elements $\mathrm{C}$ was $25.73 \%, \mathrm{~N}$ was $61.98 \%$ and $\mathrm{Cd}$ was $12.28 \%$, which illustrated that the cadmium was well doped in the $\mathrm{g}-\mathrm{C}_{3} \mathrm{~N}_{4}$ with a slight atomic ratio. All these results proved that $\mathrm{Cd} / \mathrm{g}-\mathrm{C}_{3} \mathrm{~N}_{4}$ composites were successfully constructed.

The specific BET surface area and the pore size distribution were investigated and depicted in Table S2 and Fig. S2. Obviously, the $\mathrm{Cd} / \mathrm{g}-\mathrm{C}_{3} \mathrm{~N}_{4}$ sample obtained a larger specific surface area than the monomer $\mathrm{g}-\mathrm{C}_{3} \mathrm{~N}_{4}$. Table S2 illustrated the specific surface areas and pore volume of $\mathrm{Cd} / \mathrm{g}-\mathrm{C}_{3} \mathrm{~N}_{4}$ was $16.46 \mathrm{~m} / \mathrm{g}$ and $0.123 \mathrm{~cm}^{3} / \mathrm{g}$, whereas monomer $\mathrm{g}-\mathrm{C}_{3} \mathrm{~N}_{4}$ was $13.467 \mathrm{~m}^{2} / \mathrm{g}$ and $0.077 \mathrm{~cm}^{3} / \mathrm{g}$. Undoubtedly, larger surface area and increased pore volume of $\mathrm{Cd} / \mathrm{g}-\mathrm{C}_{3} \mathrm{~N}_{4}$ could increase the contact area and attachment active sites for pollutant, and accelerate the transfer of photogenerated carriers, thus achieving a more efficient degradation rate (Chang et al. 2015). The results of $\mathrm{N}_{2}$ adsorption-desorption isotherm of g- $\mathrm{C}_{3} \mathrm{~N}_{4}$ and $\mathrm{Cd} / \mathrm{g}-\mathrm{C}_{3} \mathrm{~N}_{4}$ were exhibited that $\mathrm{g}-\mathrm{C}_{3} \mathrm{~N}_{4}$ and $10 \mathrm{Cd} / \mathrm{g}-\mathrm{C}_{3} \mathrm{~N}_{4}$ possessed a type IV curve with $\mathrm{H} 3$ hysteresis hoop, which represented the presence of slit shaped mesoporous structure accumulation of particles (Iqbal et al. 2017). These results were consistent with the previous TEM images, further confirmed that Cd was successfully doped into $\mathrm{g}-\mathrm{C}_{3} \mathrm{~N}_{4}$.

The element chemical bonding states and electronic structure details of g- $\mathrm{C}_{3} \mathrm{~N}_{4}$ and $10 \mathrm{Cd} / \mathrm{g}-\mathrm{C}_{3} \mathrm{~N}_{4}$ were investigated by XPS analysis. The full spectrum (Fig. 4a) indicated that the composite sample $10 \mathrm{Cd} / \mathrm{g}$ $\mathrm{C}_{3} \mathrm{~N}_{4}$ was consisted of $\mathrm{Cd}$ ions and pure g- $\mathrm{C}_{3} \mathrm{~N}_{4}$, which could be seen from the strong peaks of $\mathrm{C} 1 \mathrm{~s}, \mathrm{~N} 1 \mathrm{~s}$, $\mathrm{Cd} 3 \mathrm{~d}$ and a small number of $\mathrm{O}$ element. $\mathrm{C}$ and $\mathrm{N}$ elements were mainly derived from $\mathrm{g}-\mathrm{C}_{3} \mathrm{~N}_{4}$, and the presence of $\mathrm{Cd}$ was caused by $\mathrm{Cd}$ doping. Carbon nitride thermal polymerization process and surface absorption of water and oxygen were the main sources of oxygen element (Chou et al. 2016, Fang et al. 2016, Xue et al. 2019). Additionally, there was no signal of $\mathrm{Cl}$ atom (around $200 \mathrm{eV}$ ), since $\mathrm{Cl}$ atoms were evaporated during heating process (Amirthaganesan et al. 2010).

Figure $4 \mathrm{~b}$ depicted the peaks of $\mathrm{Cd} 3 \mathrm{~d}$, which were situated at $405.6 \mathrm{eV}$ and $412.4 \mathrm{eV}$ (Zhang et al. 2016a), indicating that the existence of $\mathrm{Cd}^{2+}$ in $\mathrm{Cd} / \mathrm{g}-\mathrm{C}_{3} \mathrm{~N}_{4}$ and further proving the successful doping of $\mathrm{Cd}$. Figure 4c showed the high-resolution $\mathrm{C} 1 \mathrm{~s}$ spectra, and the two sharp peaks were situated at 284.8 and $288.3 \mathrm{eV}$, respectively. The former peak at $284.8 \mathrm{eV}$ was specifically on behalf of carbon atoms (C-C bonds), namely graphite or amorphous carbon (Liu et al. 2010, Takanabe et al. 2010), and the latter sharper peak at $288.4 \mathrm{eV}$ resulted from $s p^{2} \mathrm{C}$ atoms bonded with adjacent $\mathrm{N}$ atoms inside the aromatic structure $(\mathrm{N}-\mathrm{C}=\mathrm{N})$ (Thomas et al. 2008). Three main peaks could be perceived from the high-resolution $\mathrm{N} 1 \mathrm{~s}$ spectra (Fig. 4d), and the peak at $398.8 \mathrm{eV}$ originated from $s p^{2}$-bonded $\mathrm{N}$ atoms in triazine units $(\mathrm{C}=$ $\mathrm{N}-\mathrm{C}$ ) (Li et al. 2009b, Takanabe et al. 2010), and peak at $401.1 \mathrm{eV}$ corresponded to amino groups (C-N$\mathrm{H}$ ) from the surface uncondensed bridging $\mathrm{N}$ atom (Liu et al. 2010, Thomas et al. 2008), which were similar to previously published literature (Chao et al. 2014, Matanović et al. 2015). The peak at $404 \mathrm{eV}$ was assigned to the effects of surface charging or positive charge localization in the heterocycles (Kong et al. 2018, Zhang et al. 2014, Zhang et al. 2012), or the $\pi-\pi^{*}$ excitations between the stacking interlayers 
(Li et al. 2018). Both the high-resolution $\mathrm{C} 1 \mathrm{~s}$ and $\mathrm{N}$ 1s spectra confirmed the presence of $\mathrm{g}-\mathrm{C}_{3} \mathrm{~N}_{4}$. Obviously, both $\mathrm{C} 1 \mathrm{~s}$ and $\mathrm{N} 1 \mathrm{~s}$ spectra of $10 \mathrm{Cd} / \mathrm{g}-\mathrm{C}_{3} \mathrm{~N}_{4}$ sample exhibited an upwards shifted to higher binding energies compared with pure g- $\mathrm{C}_{3} \mathrm{~N}_{4}$. Remarkably, the peak at $404.4 \mathrm{eV}$ of N $1 \mathrm{~s}$ shifted to 405.6 $\mathrm{eV}$ and possessed higher intensity. All these positive shifts may be ascribed to the electrons transfer from g- $\mathrm{C}_{3} \mathrm{~N}_{4}$ to doped $\mathrm{Cd}^{2+}$, further proving the strong interaction between $\mathrm{Cd}$ and g- $\mathrm{C}_{3} \mathrm{~N}_{4}$ (Ji et al. 2019, Yan et al. 2019).

\subsection{Optical properties}

The optical absorption characteristics was an evaluation criterion to optical properties and electronic band structures of catalyst. Additionally, the absorption range and capacity of catalysts to light affected the photocatalytic performance. The UV-vis diffuse adsorption spectrum of g- $\mathrm{C}_{3} \mathrm{~N}_{4}$ and $\mathrm{Cd} / \mathrm{g}-\mathrm{C}_{3} \mathrm{~N}_{4}$ were revealed in Fig. 5. It can be found that there was a threshold value of $465 \mathrm{~nm}$ in the intrinsic absorption of bare $\mathrm{g}-\mathrm{C}_{3} \mathrm{~N}_{4}$, which was assigned to the bandgap of $2.57 \mathrm{eV}$ (Kong et al. 2018, Wang et al. 2009b, Zhang et al. 2012), based on Tauc equation listed (Luo et al. 2017):

$(a h v)^{1 / 2}=A\left(h v-E_{g}\right)$

Where $a$ is the absorptivity, $h$ is the Planck's constant, $v$ is the light frequency, $A$ is the constant. Obviously, the absorption edge of $10 \mathrm{Cd} / \mathrm{g}-\mathrm{C}_{3} \mathrm{~N}_{4}$ had a significantly redshift compared with bare g- $\mathrm{C}_{3} \mathrm{~N}_{4}$, which illustrated that $10 \mathrm{Cd} / \mathrm{g}-\mathrm{C}_{3} \mathrm{~N}_{4}$ had a narrower band gap (2.29 eV), thus reducing the excitation energy for photogenerated carriers. Moreover, $\mathrm{Cd} / \mathrm{g}-\mathrm{C}_{3} \mathrm{~N}_{4}$ extended the adsorption edge to near $700 \mathrm{~nm}$ and the intensity of light adsorption was significantly enhanced, leading to a significant improvement in the visible light response. The spectral range covered extension is conducive to increasing the generation of electron-hole pairs, which showed effective visible light absorption activity and meant that cadmium doping into g- $\mathrm{C}_{3} \mathrm{~N}_{4}$ lattice greatly enhanced the optical response of g-C $\mathrm{N}_{4}$.

The band gap $\left(E_{g}\right)$ of $10 \mathrm{Cd} / \mathrm{g}-\mathrm{C}_{3} \mathrm{~N}_{4}$ was smaller than $\mathrm{g}-\mathrm{C}_{3} \mathrm{~N}_{4}$, which further confirmed the improvement of light absorption performance. The above analysis indicated that, with the doping of $\mathrm{Cd}$, the light absorption performance was improved and the band gaps tended to be smaller. Based on this result, it can be inferred that doping g- $\mathrm{C}_{3} \mathrm{~N}_{4}$ with $\mathrm{Cd}$ can significantly affect the electronic band structure of $\mathrm{g}-\mathrm{C}_{3} \mathrm{~N}_{4}$ and further improves the photocatalytic performance (Ge et al. 2012).

The charge separation, migration and recombination were analyzed by photoluminescence $(\mathrm{PL})$ spectra. Commonly, the weakened PL intensity meant enhanced photoinduced charge carries separation and transfer efficiency. PL spectra of $10 \mathrm{Cd} / \mathrm{g}-\mathrm{C}_{3} \mathrm{~N}_{4}$ and g- $\mathrm{C}_{3} \mathrm{~N}_{4}$ excited at $380 \mathrm{~nm}$ were indicated in Fig. $6 \mathrm{a}$. Apparently, the strong absorption peak exhibited by pristine $\mathrm{g}-\mathrm{C}_{3} \mathrm{~N}_{4}$ at $460 \mathrm{~nm}$ was consistent with the absorption edge of the UV diffuse reflection spectrum, which indicated that the recombination of the photogenerated electron - hole pair was severe (Yu et al. 2013). Once cadmium was introduced, the highest intensity position showed a gradual red-shifted from $460 \mathrm{~nm}$ of g- $\mathrm{C}_{3} \mathrm{~N}_{4}$ to $490 \mathrm{~nm}$ of $\mathrm{Cd} / \mathrm{g}-\mathrm{C}_{3} \mathrm{~N}_{4}$, which was associated with the band gap narrowing effect (Zou et al. 2019)(Gu et al. 2018). Obviously, 
the PL signals of $\mathrm{Cd} / \mathrm{g}-\mathrm{C}_{3} \mathrm{~N}_{4}$ samples significantly fell with the doping of cadmium and $10 \mathrm{Cd} / \mathrm{g}-\mathrm{C}_{3} \mathrm{~N}_{4}$ was the lowest, which illustrated that $\mathrm{Cd}$ doping restrained the recombination of photoinduced charge carriers and further proved that $10 \mathrm{Cd} / \mathrm{g}-\mathrm{C}_{3} \mathrm{~N}_{4}$ composite possessed the best removing efficiency (Thomas et al. 2008). Figure 6b was a Mott-Schottky plots with flat band potentials at a frequency of $1000 \mathrm{~Hz}$ (conduction band potential is equivalent to flat band potential for an $\mathrm{n}$-type semiconductor). Both $\mathrm{g}-\mathrm{C}_{3} \mathrm{~N}_{4}$ and $10 \mathrm{Cd} / \mathrm{g}-\mathrm{C}_{3} \mathrm{~N}_{4}$ displayed a positive slope, and the slope of $10 \mathrm{Cd} / \mathrm{g}-\mathrm{C}_{3} \mathrm{~N}_{4}$ was decreased compare with g- $\mathrm{C}_{3} \mathrm{~N}_{4}$, indicating g- $\mathrm{C}_{3} \mathrm{~N}_{4}$ and $10 \mathrm{Cd} / \mathrm{g}-\mathrm{C}_{3} \mathrm{~N}_{4}$ were both n-type semiconductors and the electron donor density in $10 \mathrm{Cd} / \mathrm{g}-\mathrm{C}_{3} \mathrm{~N}_{4}$ increased (Jun et al. 2013, Pan et al. 2018, Yang et al. 2013, Yuan et al. 2018, Zhou et al. 2014). Higher donor density is very helpful for improving photocatalytic performance because of the increased electrical conductivity and the mobility of charge carriers (Zhou et al. 2014). The conduction band potential of $\mathrm{g}-\mathrm{C}_{3} \mathrm{~N}_{4}$ and $10 \mathrm{Cd} / \mathrm{g}-\mathrm{C}_{3} \mathrm{~N}_{4}$ concluded from the Mott-Schottky plots was - $0.84 \mathrm{eV}$ and - $1.02 \mathrm{eV}$, compared with $\mathrm{Ag} / \mathrm{AgCl}$ electrodes, corresponding to $-0.64 \mathrm{eV}$ and $0.82 \mathrm{eV}$ vs normal hydrogen electrode (NHE).

Metal elements doping influenced the band edge of catalyst to a great extent, and the redox capacity of semiconductors were evaluated via the band edge position of conduction $\left(\mathrm{E}_{\mathrm{CB}}\right)$ and the valence $\left(\mathrm{E}_{\mathrm{VB}}\right)$, which were formed by N2p and C2p orbital of $g-C_{3} N_{4}$, respectively (Xiong et al. 2016). The $E_{C B}$ and $E_{V B}$ could obtained from following (Zhang et al. 2010):

$E_{C B}=X-E^{e}-0.5 E_{g}$

$E_{V B}=E_{C B}+E_{g}$

Where $\mathrm{X}$ is electronegativity and $\mathrm{E}^{\mathrm{e}}$ is $4.5 \mathrm{eV}$. Fig. S3 revealed the $\mathrm{E}_{\mathrm{VB}}$ and $\mathrm{E}_{\mathrm{CB}}$ positions of as-prepared materials. For pure $\mathrm{g}-\mathrm{C}_{3} \mathrm{~N}_{4}$, the $\mathrm{E}_{\mathrm{VB}}$ was situated at $1.93 \mathrm{eV}$, on the basis of the experimental $\mathrm{E}_{\mathrm{g}}(2.57 \mathrm{eV})$, the $E_{C B}$ was $-0.64 \mathrm{eV}$. Meanwhile, the $E_{V B}$ of $10 \mathrm{Cd} / \mathrm{g}-\mathrm{C}_{3} \mathrm{~N}_{4}$ decreased to $1.47 \mathrm{eV}$ and the $\mathrm{E}_{\mathrm{CB}}$ climbed to $-0.82 \mathrm{eV}$.

Other photoelectrochemical techniques such as EIS and photocurrent response measurement have been employed to investigate the movement process of photoinduced electrons in prepared materials.

Figure $6 \mathrm{c}$ revealed the photocurrent responses of $\mathrm{g}-\mathrm{C}_{3} \mathrm{~N}_{4}$ and $\mathrm{Cd} / \mathrm{g}-\mathrm{C}_{3} \mathrm{~N}_{4}$ were repeatable and outstanding photostability under successive on/off illumination cycles. In addition, the photocurrent of g- $\mathrm{C}_{3} \mathrm{~N}_{4}$ could be negligible, and significantly increased photocurrent response density of $10 \mathrm{Cd} / \mathrm{g}-\mathrm{C}_{3} \mathrm{~N}_{4}$ was observed, which indicated Cd doping increased the conductivity and separation of electron and hole of $\mathrm{g}-\mathrm{C}_{3} \mathrm{~N}_{4}(\operatorname{Ren}$ et al. 2017). Electrochemical impedance spectroscopy (EIS) was another method to evaluated the separation and transfer efficiency of photoinduced carriers. The smaller arc radius suggested smaller transfer resistance, namely the better separation efficiency, which meant lower recombination of photoinduced carriers (Lu et al. 2017). The equivalent electrical circuit is illustrated in Fig. 6d, which contained electrolyte solution resistance (Rs), double-layer capacitance (CPE), and charge-transfer resistance (Rp) (Yang et al. 2002). As depicted in Fig. $6 \mathrm{~d}$, the arc radius of $10 \mathrm{Cd} / \mathrm{g}-\mathrm{C}_{3} \mathrm{~N}_{4}$ was smaller than 
pristine $\mathrm{g}-\mathrm{C}_{3} \mathrm{~N}_{4}$, which reflected that the charge-transfer resistance of $\mathrm{Cd} / \mathrm{g}-\mathrm{C}_{3} \mathrm{~N}_{4}$ was much lower than that of pristine g- $\mathrm{C}_{3} \mathrm{~N}_{4}$, and $\mathrm{Cd} / \mathrm{g}-\mathrm{C}_{3} \mathrm{~N}_{4}$ possessed high-efficiency photoinduced carriers separation ability and faster interfacial charge transport level (Zhu et al. 2015).

\subsection{Photocatalytic activities}

To test the effect of different content of $\mathrm{Cd}$ doping on the degradation performance of the catalyst, we carried out a group of comparative degradation experiments with only changing the content of cadmium under visible-light irradiation $(\lambda>420 \mathrm{~nm})$ at room temperature. In this paper, TC was selected as the main contaminant due to the high stability under visible light irradiation. Undoubtedly, the more TC degraded, the better degradation performance of the catalyst. As illustrated in Fig. 7a, the degradation rate of TC without catalysts can be neglected. Furthermore, the adsorption capacity of the doped catalyst is slightly larger than that of pristine $\mathrm{g}-\mathrm{C}_{3} \mathrm{~N}_{4}$ during the dark stage, which corresponds to an increase in the specific surface area of the catalyst after doping with $\mathrm{Cd}$. However, the photocatalytic activity of $\mathrm{Cd} / \mathrm{g}-\mathrm{C}_{3} \mathrm{~N}_{4}$ composites first increases and then decreases with the increase of Cd content, which probably indicates that excessive $\mathrm{Cd}$ could serve as photo-carrier's recombination center and inhibited the photocatalytic performance. Moreover, the introduction of excessive $\mathrm{Cd}$ may reduce the photo-adsorption ability and cover the surface active site of catalyst, thus hindering the effective migration of charge carriers (Li et al. 2009a, Zhang et al. 2016b, Zhang et al. 2010). Obviously, Cd/g- $\mathrm{C}_{3} \mathrm{~N}_{4}$ samples exhibits great increased photo-decomposition efficiency compared with pure $\mathrm{g}-\mathrm{C}_{3} \mathrm{~N}_{4}(45.1 \%)$ and the $10 \mathrm{Cd} / \mathrm{g}$ $\mathrm{C}_{3} \mathrm{~N}_{4}$ sample showed the greatest photocatalytic performance (89.09\%) after an hour light irradiation, which can be attributed to the effective separation and transfer of photogenerated charges originating from the composite interface. All these results concluded that Cd load had significantly improved the photodegradation efficiency.

The pseudo-first-order kinetic model was an alternative analytical method, which could further investigate the performance of the catalyst, the formula is express as the following:

$\ln \left(\mathrm{C}_{\mathrm{t}} / \mathrm{C}_{0}\right)=-\mathrm{K}_{\mathrm{app}} \mathrm{t}$

$\mathrm{C}_{0}$ is the initial concentrations and $\mathrm{C}_{\mathrm{t}}$ is the concentrations at time $\mathrm{t}$ of $\mathrm{TC}, \mathrm{K}_{\text {app }}$ is reaction rate constant $\left(\min ^{-1}\right)$, respective. Fig. S4 presented the pseudo-first-order kinetic plots of $\mathrm{Cd} / \mathrm{g}-\mathrm{C}_{3} \mathrm{~N}_{4}$ and pristine g$\mathrm{C}_{3} \mathrm{~N}_{4}$. Under the same condition, the degradation rate constant $\mathrm{K}_{\text {app }}$ of $10 \mathrm{Cd} / \mathrm{C}_{3} \mathrm{~N}_{4}\left(3.605 \times 10^{-2} \mathrm{~min}^{-1}\right)$ is about 3.6 times that of pristine $\mathrm{g}-\mathrm{C}_{3} \mathrm{~N}_{4}\left(0.99 \times 10^{-2} \mathrm{~min}^{-1}\right)$, demonstrating that $10 \mathrm{Cd} / \mathrm{g}-\mathrm{C}_{3} \mathrm{~N}_{4}$ had the best photocatalytic performance, which consisted with the above experimental results. In conclusion, the introduction of cadmium could enhance photodegradation efficiency under light condition.

The effects of different reaction conditions, such as initial concentration of TC, different catalyst dosage and $\mathrm{pH}$ value, were studied to meet practical application. Figure $7 \mathrm{~b}$ displayed the influence of different catalyst dosages on TC photodegradation. It was apparent that the removal rate of TC was enhanced 
slightly as the dosages increased $(0.4,0.6,0.8$ and $1.0 \mathrm{~g} / \mathrm{L})$ and the catalyst dosages at $1.0 \mathrm{~g} / \mathrm{L}$ showed the best photocatalytic performance.

The complete removal of TC in the photocatalytic process are crucial to prevent secondary pollution. Therefore, the ability of mineralization is also an important indicator of photocatalysts. Fig. S5 clearly indicated that the mineralization efficiency of TC reached to $34 \%$ within 60 min visible light irradiation, which confirmed that $\mathrm{Cd} / \mathrm{g}-\mathrm{C}_{3} \mathrm{~N}_{4}$ could actually degrade $\mathrm{TC}$ into small molecule intermediate compounds or $\mathrm{CO}_{2}$ and $\mathrm{H}_{2} \mathrm{O}$. The results indicated that $\mathrm{Cd} / \mathrm{g}-\mathrm{C}_{3} \mathrm{~N}_{4}$ is an excellent photocatalyst for TC degradation.

In this experiment, diluted hydrochloric acid and sodium hydroxide were used to adjust the initial $\mathrm{pH}$. Figure $7 \mathrm{c}$ indicated that $10 \mathrm{Cd} / \mathrm{g}-\mathrm{C}_{3} \mathrm{~N}_{4}$ performed well in wide $\mathrm{pH}$ range. Obviously, the degradation efficiency of $\mathrm{TC}$ was $77.2 \%$ at $\mathrm{pH}=11$. While the $\mathrm{pH}$ decreased to 7 , the degradation efficiency got up to $79.9 \%$, and while the $\mathrm{pH}$ decreased to 5 , the degradation efficiency increased to $88.5 \%$. It was concluded that photodegradation efficiency was higher in acidic environment than neutral environment and alkaline environment. Initial concentration of TC also had a strong effect on photocatalyst activities in practical application. It could be clearly detected that the removal rates of TC were $88.5 \%, 78.6 \%, 56.9 \%$ and $50.3 \%$ when the initial concentration of TC was 10, 20, 30 and $40 \mathrm{mg} / \mathrm{L}$ (Fig. 7d). This result indicated that the degradation rate was higher at low pollutant concentrations and then decreased with pollutant concentration increased. Two possible reasons could be proposed to elucidate this tendency. Firstly, high concentrations of contaminants might accumulate at the surface of catalyst, thus inhibiting the light absorption capacity. Secondly, intermediate products produced in the process of pollutant degradation might occupy the active site, so that pollutant had no contact with the catalyst.

Stability is an effective criterion to evaluated the practicability for semiconductor catalyst, thus, it is of great significance to assess stability of catalysts. The stability tests were carried out by reusing the catalyst under equal condition. It should be noted that the sample was cleaned with ethanol and deionized water, and then, it was dried in an oven at $60^{\circ} \mathrm{C}$ after each experiment. Figure 8a depicted that the TC degradation rates were slightly descending with the reuse of $\mathrm{Cd} / \mathrm{g}-\mathrm{C}_{3} \mathrm{~N}_{4}$, which could be attributed to the small loss of sample during the collection after each cycle. The finial removal efficiency still maintained at a relative high level, which was about $80.03 \%$. Moreover, no obvious peak changes were found by XRD analysis of the used photocatalyst, indicating the outstanding stability of $\mathrm{Cd} / \mathrm{g}-\mathrm{C}_{3} \mathrm{~N}_{4}$. Therefore, the $\mathrm{Cd} / \mathrm{g}-\mathrm{C}_{3} \mathrm{~N}_{4}$ photocatalyst could be deemed as stable materials during the photocatalytic degradation of TC.

\subsection{Mechanism}

The trapping experiments was used to determine the decisive active species participating in the degradation process ( $\mathrm{Li}$ et al. 2015). Ethylenediaminetetraacetic acid disodium salt (EDTA-2Na), anhydrous ethanol, isopropanol (IPA), 4-hydroxy-2,2,6,6-tetramethylpiperidinyloxy (TEMPO) were added into reaction solution as scavengers to capture $\mathrm{h}^{+}, \cdot \mathrm{OH}$ and $\cdot \mathrm{O}_{2}{ }^{-}$, respectively. Figure $9 \mathrm{a}$ and Fig. $9 \mathrm{~b}$ illustrated that the degradation rate of TC was obviously suppressed by EDTA-2Na and descended from 
$\sim 90 \%$ to $75.38 \%$, indicating that $\mathrm{h}^{+}$was the main active species of $\mathrm{Cd} / \mathrm{g}-\mathrm{C}_{3} \mathrm{~N}_{4}$ material. On the other hand, the degradation rates decreased slightly when the TEMPO and IPA were added, revealing that $\cdot \mathrm{O}_{2}{ }^{-}$ and $\cdot \mathrm{OH}$ played auxiliary roles in photocatalytic degradation (Yan et al. 2010, Yu et al. 2018).

Electrochemical impedance spectroscopy (ESR) was carried out to verify the above results. As we could see from Fig. 9c and Fig. 9d, it is hard to seen the ups and downs signals of free radicals under dark conditions in $\mathrm{Cd} / \mathrm{g}-\mathrm{C}_{3} \mathrm{~N}_{4}$. However, a strong intensity signals of $\cdot \mathrm{OH}$ and $\cdot \mathrm{O}_{2}{ }^{-}$radicals could be found under the visible light illumination, which proved that light is prerequisite for catalyst to product active species.

According to all aforementioned results, the introduction of Cd speed up the transmission of electron-hole pairs and decrease the recombination rate of photogenerated charge carriers, providing more reactive sites and accelerating cross-plane diffusion in g- $\mathrm{C}_{3} \mathrm{~N}_{4}$ nanosheets (Iqbal et al. 2017), thus achieving the enhanced photocatalytic property. A brief mechanism of TC degradation was summarized in Scheme 1. The electrons and holes were firstly generated under light irradiation, and the electrons transferred from valence band to conduction band spontaneously, thus leaving holes at valence band and electrons accumulated at conduction band (Eq. (1)). Then, the absorbed $\mathrm{O}_{2}$ reacted with electrons to formed superoxide radical (Eq. (2)). Further, the surplus electrons reacted with superoxide radical to formed hydrogen peroxide $\left(\mathrm{H}_{2} \mathrm{O}_{2}\right)$ (Eq. (3)). As listed in Fig. $\mathrm{S} 3$ the $\mathrm{E}_{\mathrm{CB}}$ of $\mathrm{Cd} / \mathrm{g}-\mathrm{C}_{3} \mathrm{~N}_{4}$ was $-0.82 \mathrm{eV}$, which were negative than redox potential of $\mathrm{O}_{2} / \cdot \mathrm{O}_{2}^{-}(-0.33 \mathrm{eV}$ vs NHE), thus the accumulated electrons could react with $\mathrm{O}_{2}$ to formed $\cdot \mathrm{O}_{2}{ }^{-}$. But the $\mathrm{E}_{\mathrm{VB}}$ of $\mathrm{Cd} / \mathrm{g}-\mathrm{C}_{3} \mathrm{~N}_{4}$ was $+1.47 \mathrm{eV}$, which were negative than redox potential of $\mathrm{OH}^{-} / \cdot \mathrm{OH}(2.40 \mathrm{eV}$ vs $\mathrm{NHE})$, consequently, the accumulated holes could not react with $\mathrm{OH}^{-}$to formed $\cdot \mathrm{OH}$, which was not consistent with ESR result. Therefore the $\cdot \mathrm{OH}$ probably derived from $\mathrm{H}_{2} \mathrm{O}_{2}$ decomposition (Eq. (4)). From what has been discussed above, $\cdot \mathrm{O}_{2}{ }^{-}, \cdot \mathrm{OH}$ and $\mathrm{h}^{+}$were worked together to degrade TC into small molecules (Eq. (5)), which was in good agreement with ESR analysis and quenching tests. The reaction equations may be involved in the photocatalytic reaction process are shown below (Jia et al. 2020).

$\mathrm{Cd} / \mathrm{g}-\mathrm{C}_{3} \mathrm{~N}_{4}+\mathrm{hv} \rightarrow \mathrm{e}^{-}+\mathrm{h}^{+}(1)$

$\mathrm{O}_{2}+\mathrm{e}^{-} \rightarrow \cdot \mathrm{O}_{2}^{-}(2)$

$\cdot \mathrm{O}_{2}^{-}+\mathrm{e}^{-}+2 \mathrm{H}^{+} \rightarrow \mathrm{H}_{2} \mathrm{O}_{2}(3)$

$\mathrm{H}_{2} \mathrm{O}_{2}+\mathrm{e}^{-} \rightarrow \cdot \mathrm{OH}+\mathrm{OH}^{-}(4)$

$\cdot \mathrm{O}_{2}^{-}+\mathrm{h}^{+}+\cdot \mathrm{OH}+\mathrm{TC} \rightarrow \mathrm{H}_{2} \mathrm{O}+\mathrm{CO}_{2}+$ intermediate products (5)

\section{Conclusion}


In summary, $\mathrm{Cd} / \mathrm{g}-\mathrm{C}_{3} \mathrm{~N}_{4}$ composites were prepared by mixing dopant agent $\mathrm{CdCl}_{2}$ with $\mathrm{g}-\mathrm{C}_{3} \mathrm{~N}_{4}$ in ethanol $/ \mathrm{H}_{2} \mathrm{O}$ solution. The degradation experiments demonstrated explicitly that the photocatalytic activity of g- $\mathrm{C}_{3} \mathrm{~N}_{4}$ could be enhanced significantly with the doping of Cd elements, and the best removal efficiency was $89.09 \%$, which was 2.0 -times enhanced in comparison with pure g- $\mathrm{C}_{3} \mathrm{~N}_{4}(45.1 \%)$. Based on the characterization analysis, the enhanced photocatalytic performance could be ascribed to the improved the migration and separation of the photogenerated carriers. Meanwhile, the increased surface area and mesoporous structure extended the photo-absorption region, accelerating the transfer efficiency of light-generated charges. Concurrently, the ultrathin structure and the increased surface area could provide more active sites along with a shortened electron-transfer pathway, which was conducive to inhibiting the recombination of the photogenerated electrons and holes. The present work is expected to provide a new way for metal doped photocatalyst.

\section{Declarations}

Authors contributions $\mathrm{YZ}$ : Responsible for writing papers, conducting experiments, drawing the chart and analyzing the characterization part. HQ, QL, ZW, HW, ZW, YH, QT, CW: Responsible for reviewing the article and providing suggestions for revisions. PX: Responsible for the revision and typesetting of the paper.

Funding All the authors would like to thank the Program for the National Natural Science Foundation of China which financially supported this study. All authors are grateful to their representative universities/institutes for providing experimental facilities and financial support.

Availability of data and materials All data and materials generated or analyzed during this study are included in the manuscript

Ethical approval Not applicable.

Consent to participate Not applicable.

Consent to publish Not applicable.

Competing interests The authors declare that they have no competing interests.

\section{References}

Abbott D (2010): Keeping the Energy Debate Clean: How Do We Supply the World's Energy Needs? Proceedings of the IEEE 98, 42-66

Amirthaganesan G, Dhanabal T, Nanthini K, Dhandapani M (2010): Thermal and FTIR spectral characterization of diammonium tetrachloromanganate (II) monohydrate crystals. Materials Letters MATER LETT 64, 264-266 
Butchosa C, Guiglion P, Zwijnenburg MA (2014): Carbon Nitride Photocatalysts for Water Splitting: A Computational Perspective. The Journal of Physical Chemistry C 118, 24833-24842

Chai B, Peng T, Mao J, Li K, Zan L (2012): Graphitic carbon nitride $\left(\mathrm{g}-\mathrm{C}_{3} \mathrm{~N}_{4}\right)-\mathrm{Pt}-\mathrm{TiO}{ }_{2}$ nanocomposite as an efficient photocatalyst for hydrogen production under visible light irradiation. Physical chemistry chemical physics : PCCP 14

Chan D, Yu J, Yecheng I, Hu Z (2017): A metal-free composite photocatalyst of graphene quantum dots deposited on red phosphorus. Journal of Environmental Sciences 60

Chang F, Li C, Luo J, Xie Y, Deng B, Hu X (2015): Enhanced visible-light-driven photocatalytic performance of porous graphitic carbon nitride. Applied Surface Science 358, 270-277

Chang F, Yan W, Cheng W, Wu F, Deng B, Hu X (2018): The construction and enhanced photocatalytic performance of binary composite $\mathrm{S} / \mathrm{g}-\mathrm{C}_{3} \mathrm{~N}_{4}$. Mater. Sci. Semicond. Process $87,1-6$

Chao K, Liao H, Shyue J, Lian S-S (2014): Corrosion Behavior of High Nitrogen Nickel-Free Fe-16Cr-MnMo-N Stainless Steels. Metallurgical and Materials Transactions B 45

Chen X, Peng X, Jiang L, Yuan X-Z, Yu H, Hou W, Zhang J, Xia Q (2020): Recent advances in titanium metal-organic frameworks and their derived materials: Features, fabrication, and photocatalytic applications. Chemical Engineering Journal 395, 125080

Chou S-Y, Chen C-C, Dai Y-M, Lin J-H, Lee WW (2016): Novel synthesis of bismuth oxyiodide/graphitic carbon nitride nanocomposites with enhanced visible-light photocatalytic activity. RSC Advances 6 , 33478-33491

Dong G, Zhao K, Zhang L (2012): Carbon self-doping induced high electronic conductivity and photoreactivity of g- $\mathrm{C}_{3} \mathrm{~N}_{4}$. Chemical communications (Cambridge, England) $48,6178-80$

Fan J, Qin H, Jiang S (2019): Mn-doped g- $\mathrm{C}_{3} \mathrm{~N}_{4}$ composite to activate peroxymonosulfate for acetaminophen degradation: The role of superoxide anion and singlet oxygen. Chemical Engineering Journal 359, 723-732

Fan M, Cj S, Chen T, Yan X, Dongbo X, Gu W, Shi W, xiao I (2016): Visible-Light-Drived High Photocatalytic Activities of $\mathrm{Cu} / \mathrm{g}-\mathrm{C}_{3} \mathrm{~N}_{4}$ photocatalysts for Hydrogen Production. RSC Adv. 6

Fang LJ, Wang XL, Zhao JJ, Li YH, Wang YL, Du XL, He ZF, Zeng HD, Yang HG (2016): One-step fabrication of porous oxygen-doped $\mathrm{g}-\mathrm{C}_{3} \mathrm{~N}_{4}$ with feeble nitrogen vacancies for enhanced photocatalytic performance. Chemical Communications 52, 14408-14411

Gao H, Yan S, Wang J, Huang YA, Wang P, Li Z, Zou Z (2013): Towards efficient solar hydrogen production by intercalated carbon nitride photocatalyst. Physical Chemistry Chemical Physics 15, 18077-18084 
Gao J, Zhou Y Fau - Li Z, Li Z Fau - Yan S, Yan S Fau - Wang N, Wang N Fau - Zou Z, Zou Z High-yield synthesis of millimetre-long, semiconducting carbon nitride nanotubes with intense photoluminescence emission and reproducible photoconductivity.

Gao J, Zhou Y, Li Z, Yan S, Wang N, Zou Z (2012): High-yield synthesis of millimetre-long, semiconducting carbon nitride nanotubes with intense photoluminescence emission and reproducible photoconductivity. Nanoscale 4, 3687-92

Ge L, Han C, Liu J, Li Y (2011): Enhanced visible light photocatalytic activity of novel polymeric g- $\mathrm{C}_{3} \mathrm{~N}_{4}$ loaded with Ag nanoparticles. Applied Catalysis A: General 409-410, 215-222

Ge L, Zuo F, Liu J, Ma Q, Wang C, Sun D, Bartels L, Feng P (2012): Synthesis and Efficient Visible Light Photocatalytic Hydrogen Evolution of Polymeric $\mathrm{g}-\mathrm{C}_{3} \mathrm{~N}_{4}$ Coupled with CdS Quantum Dots. The Journal of Physical Chemistry C 116, 13708-13714

Gu Y, Yu Y, Zou J, Shen T, Xu Q, Yue X, Meng J, Wang J (2018): The ultra-rapid synthesis of $r G 0 / g-C_{3} N_{4}$ composite via microwave heating with enhanced photocatalytic performance. Materials Letters 232

Huang D, Chen S, Zeng G, Gong X, Zhou C, Cheng M, Xue W, Yan X, Li J (2019): Artificial Z-scheme photocatalytic system: What have been done and where to go? Coordination Chemistry Reviews 385, 4480

Iqbal W, Dong C, Xing M, Tan X, Zhang J (2017): Eco-friendly one-pot synthesis of well-adorned mesoporous $\mathrm{g}-\mathrm{C}_{3} \mathrm{~N}_{4}$ with efficiently enhanced visible light photocatalytic activity. Catal. Sci. Technol. 7

Ji C, Du C, Steinkruger JD, Zhou C, Yang S (2019): In-situ hydrothermal fabrication of CdS/g-C $\mathrm{N}_{4}$ nanocomposites for enhanced photocatalytic water splitting. Materials Letters 240, 128-131

Jia J, Jiang C, Zhang X, Li P, Xiong J, Zhang Z, Wu T, Wang Y (2019): Urea-modified carbon quantum dots as electron mediator decorated $\mathrm{g}-\mathrm{C}_{3} \mathrm{~N}_{4} / \mathrm{WO}_{3}$ with enhanced visible-light photocatalytic activity and mechanism insight. Applied Surface Science 495, 143524

Jia J, Zhang X, Jiang C, Huang W, Wang Y (2020): Visible-light-driven nitrogen-doped carbon quantum dots decorated $\mathrm{g}-\mathrm{C}_{3} \mathrm{~N}_{4} / \mathrm{Bi} 2 \mathrm{WO}_{6} \mathrm{Z}$-scheme composite with enhanced photocatalytic activity and mechanism insight. Journal of Alloys and Compounds 835, 155180

Jun Y-S, Lee E, Wang X, Hong W, Stucky G, Thomas A (2013): From Melamine-Cyanuric Acid Supramolecular Aggregates to Carbon Nitride Hollow Spheres. Advanced Functional Materials, n/a-n/a Katsumata H, Sakai T, Suzuki T, Knaeco S (2014): Highly Efficient Photocatalytic Activity of g$\mathrm{C}_{3} \mathrm{~N}_{4} / \mathrm{Ag}_{3} \mathrm{PO}_{4}$ Hybrid Photocatalysts through Z-Scheme Photocatalytic Mechanism under Visible Light. Ind. Eng. Chem. Res. 53, 8018-8025 
Kong L, Yujin J, Dang Z, Yan J, Li P, Li Y (2018): g- $\mathrm{C}_{3} \mathrm{~N}_{4}$ Loading Black Phosphorus Quantum Dot for Efficient and Stable Photocatalytic $\mathrm{H}_{2}$ Generation under Visible Light. Advanced Functional Materials 28 , 1800668

Li H, Liu Y, Gao X, Fu C, Wang X (2015): Facile Synthesis and Enhanced Visible-Light Photocatalysis of Graphitic Carbon Nitride Composite Semiconductors. ChemSusChem 8

Li H, Shan C, Pan B (2018): Fe(III)-Doped g- $\mathrm{C}_{3} \mathrm{~N}_{4}$ Mediated Peroxymonosulfate Activation for Selective Degradation of Phenolic Compounds via High-Valent Iron-Oxo Species. Environmental Science \& Technology 52, 2197-2205

Li J, Xu J, Dai W-L, Li H, Fan K (2009a): Direct hydro-alcohol thermal synthesis of special core-shell structured Fe-doped titania microspheres with extended visible light response and enhanced photoactivity. Applied Catalysis B: Environmental 85, 162-170

Li X, Zhang J, Shen L, Yanmei m, Lei W, Cui Q, Zou G (2009b): Preparation and characterization of graphitic carbon nitride through pyrolysis of melamine. Applied Physics A 94, 387-392

Liu G, Niu P, Smith S, Chen Z-G, Lu M, Cheng H-M (2010): Unique Electronic Structure Induced High Photoreactivity of Sulfur-Doped Graphitic $\mathrm{C}_{3} \mathrm{~N}_{4}$. Journal of the American Chemical Society $132,11642-8$

Liu J, Liu Y, Naiyun L, Han Y, Zhang X, Huang H, Lifshitz Y, Lee S-T, Zhong J, Kang ZH (2015): Chemlnform Abstract: Metal-Free Efficient Photocatalyst for Stable Visible Water Splitting via a Two-Electron Pathway. Science (New York, N.Y.) 347, 970-4

Liu S, Li D, Sun H, Ang HM, Tadé MO, Wang S (2016): Oxygen functional groups in graphitic carbon nitride for enhanced photocatalysis. Journal of Colloid and Interface Science 468, 176-182

Liu W, Wang M, Xu C, Chen S (2012): Facile synthesis of g- $\mathrm{C}_{3} \mathrm{~N}_{4} / \mathrm{ZnO}$ composite with enhanced visible light photooxidation and photoreduction properties. Chemical Engineering Journal 209, 386-393

Liu Y, He M, Guo R, Fang Z, Kang S, Ma Z, Dong M, Wang W, Cui L (2020): Ultrastable metal-free nearinfrared-driven photocatalysts for $\mathrm{H}_{2}$ production based on protonated $2 \mathrm{D} \mathrm{g}-\mathrm{C}_{3} \mathrm{~N}_{4}$ sensitized with Chlorin e6. Applied Catalysis B: Environmental 260, 118137

Lu Q, Deng J, Hou Y, Wang H, Li H, Zhang Y (2015): One-step electrochemical synthesis of ultrathin graphitic carbon nitride nanosheets and their application to the detection of uric acid. Chemical Communications 51, 12251-12253

Lu Z, Song W, Ouyang C, Wang H, Zeng D, Xie C (2017): Enhanced visible-light photocatalytic performance of highly-dispersed $\mathrm{Pt} / \mathrm{g}-\mathrm{C}_{3} \mathrm{~N}_{4}$ nanocomposites by one-step solvothermal treatment. RSC Adv. 7, 33552-33557 
Luo L, Zhang A, Janik MJ, Li K, Song C, Guo X (2017): Facile fabrication of ordered mesoporous graphitic carbon nitride for RhB photocatalytic degradation. Applied Surface Science 396, 78-84

Matanović I, Babanova S, lii A, Serov A, Artyushkova K, Atanassov P (2015): Bio-inspired Design of Electrocatalysts for Oxalate Oxidation: a Combined Experimental and Computational Study of Mn-N-C Catalyst. Phys. Chem. Chem. Phys. 17

McCauley S, Stephens J (2012): Green energy clusters and socio-technical transitions: Analysis of a sustainable energy cluster for regional economic development in Central Massachusetts, USA. Sustainability Science 7

Narkbuakaew T, Sujaridworakun P (2020): Synthesis of Tri-S-Triazine Based g- $\mathrm{C}_{3} \mathrm{~N}_{4}$ Photocatalyst for Cationic Rhodamine B Degradation under Visible Light. Top. Catal. 63, 1086-1096

Ong W-J, Tan L-L, Ng YH, Yong S-T, Chai S-P (2016): Graphitic Carbon Nitride $\left(\mathrm{g}-\mathrm{C}_{3} \mathrm{~N}_{4}\right)$-Based Photocatalysts for Artificial Photosynthesis and Environmental Remediation: Are We a Step Closer To Achieving Sustainability? Chemical Reviews 116, 7159-7329

Ou M, Zhong Q, Zhang S, Yu L (2015): Ultrasound assisted synthesis of heterogeneous g- $\mathrm{C}_{3} \mathrm{~N}_{4} / \mathrm{BiVO}_{4}$ composites and their visible-light-induced photocatalytic oxidation of NO in gas phase. Journal of Alloys and Compounds 626, 401-409

Pan J, Feng S, Zhao C, Dong Z, Wang B, Wang J, Song C, Zheng Y, Li C (2018): The enhanced photocatalytic hydrogen production of the fusiform g- $\mathrm{C}_{3} \mathrm{~N}_{4}$ modification $\mathrm{CaTiO}_{3}$ nano-heterojunction. International Journal of Hydrogen Energy 43

Park S-S, Chu S-W, Xue C, Zhao D, Ha C-S (2011): Facile synthesis of mesoporous carbon nitrides using the incipient wetness method and the application as hydrogen adsorbent. J. Mater. Chem. 21, 1080110807

Qi Y, Liang Q, Lv R, Shen W, Kang F, Huang Z-H (2018): Synthesis and photocatalytic activity of mesoporous g- $\mathrm{C}_{3} \mathrm{~N}_{4} / \mathrm{MoS}_{2}$ hybrid catalysts. R Soc Open Sci 5, 180187-180187

Ren K, Yin P, Zhou Y, Cao X, Dong C, Cui L, Liu H, Du X (2017): Localized Defects on Copper Sulfide Surface for Enhanced Plasmon Resonance and Water Splitting. Small 13, 1700867

Samanta S, Martha S, Parida K (2014): Facile Synthesis of Au/g- $\mathrm{C}_{3} \mathrm{~N}_{4}$ Nanocomposites: An Inorganic/Organic Hybrid Plasmonic Photocatalyst with Enhanced Hydrogen Gas Evolution Under VisibleLight Irradiation. ChemCatChem 6

Schwinghammer K, Mesch M, Duppel V, Ziegler C, Senker J, Lotsch B (2014): Crystalline Carbon Nitride Nanosheets for Improved Visible-Light Hydrogen Evolution. J. Am. Chem. Soc. 136 
Shi J, Chen G, Zeng G, Chen A, He K, Huang Z, Hu L, Zeng J, Wu J, Liu W (2018): Hydrothermal synthesis of graphene wrapped $\mathrm{Fe}$-doped $\mathrm{TiO}_{2}$ nanospheres with high photocatalysis performance. Ceramics International 44, 7473-7480

Sobhana S S L, Devi M, Sastry T, Mandal A (2011): CdS quantum dots for measurement of the sizedependent optical properties of thiol capping. J. Nanopart. Res. 13, 1747-1757

Song B, Chen M, Ye S, Xu P, Zeng G, Gong J, Li J, Zhang P, Cao W (2019): Effects of multi-walled carbon nanotubes on metabolic function of the microbial community in riverine sediment contaminated with phenanthrene. Carbon 144, 1-7

Tahir M, Cao C, Butt F, Mahmood A, Idrees F, Hussain S, Tanveer M, Ali Z, Aslam I (2013): Multifunctional g- $\mathrm{C}_{3} \mathrm{~N}_{4}$ Nanofibers: A Template-Free Fabrication and Enhanced Optical, Electrochemical, and Photocatalyst Properties. ACS Appl. Mater. Interfaces 6

Takanabe K, Kamata K, Wang X, Antonietti M, Kubota J, Domen K (2010): Photocatalytic hydrogen evolution on dye-sensitized mesoporous carbon nitride photocatalyst with magnesium phthalocyanine. Physical chemistry chemical physics : PCCP 12, 13020-5

Thaweesak S, Wang S, Lyu M, Xiao M, Peerakiatkhajohn P, Wang L (2017): Boron-doped graphitic carbon nitride nanosheets for enhanced visible-light driven photocatalytic water splitting. Dalton Trans. 46

Thomas A, Fischer A, Goettmann F, Antonietti M, Müller J-O, Schlögl R, Carlsson J (2008): ChemInform Abstract: Graphitic Carbon Nitride Materials: Variation of Structure and Morphology and Their Use as Metal-Free Catalysts. Journal of Materials Chemistry, v.18, 4893-4908 (2008) 40

Tonda S, Kumar S, Kandula S, Shanker V (2014): Fe-doped and -mediated graphitic carbon nitride nanosheets for enhanced photocatalytic performance under natural sunlight. Journal of Materials Chemistry A: Materials for Energy and Sustainability 2, 6772

Wang H, Wang H, Wang Z, Tang L, Zeng G, Xu P, Chen M, Xiong T, Zhou C, Li X, Huang D, Zhu Y, Wang Z, Tang J (2020a): Covalent organic framework photocatalysts: structures and applications. Chemical Society Reviews 49, 4135-4165

Wang Q, Yang Z (2016): Industrial water pollution, water environment treatment, and health risks in China. Environmental Pollution 218, 358-365

Wang W, Xu P, Chen M, Zeng G, Zhang C, Zhou C, Yang Y, Huang D, Lai C, Cheng M, Hu L, Xiong W, Guo H, Zhou M (2018a): Alkali Metal-Assisted Synthesis of Graphite Carbon Nitride with Tunable Band-Gap for Enhanced Visible-Light-Driven Photocatalytic Performance. ACS Sustainable Chemistry \& Engineering 6, 15503-15516 
Wang X, Maeda K, Thomas A, Takanabe K, Xin G, Carlsson J, Domen K, Antonietti M (2008): A metal-free polymeric photocatalyst for hydrogen production from water under visible light. Nature materials $8,76-80$

Wang X, Chen X, Thomas A, Fu X, Antonietti M (2009a): Metal-Containing Carbon Nitride Compounds: A New Functional Organic-Metal Hybrid Material. Advanced Materials 21, 1609-1612

Wang X, Maeda K, Thomas A, Takanabe K, Xin G, Carlsson JM, Domen K, Antonietti M (2009b): A metalfree polymeric photocatalyst for hydrogen production from water under visible light. Nature Materials 8 , 76-80

Wang Y, Yang W, Chen X, Wang J, Zhu Y (2018b): Photocatalytic activity enhancement of core-shell structure g- $\mathrm{C}_{3} \mathrm{~N}_{4} @ \mathrm{TiO}_{2}$ via controlled ultrathin g- $\mathrm{C}_{3} \mathrm{~N}_{4}$ layer. Applied Catalysis B: Environmental 220, 337347

Wang Z, Chen M, Huang D, Zeng G, Xu P, Zhou C, Lai C, Wang H, Cheng M, Wang W (2019): Multiply structural optimized strategies for bismuth oxyhalide photocatalysis and their environmental application. Chemical Engineering Journal 374, 1025-1045

Wang Z, Wang H, Zeng Z, Zeng G, Xu P, Xiao R, Huang D, Chen X, He L, Zhou C, Yang Y, Wang Z, Wang W, Xiong W (2020b): Metal-organic frameworks derived $\mathrm{Bi}_{2} \mathrm{O}_{2} \mathrm{CO}_{3}$ /porous carbon nitride: A nanosized Zscheme systems with enhanced photocatalytic activity. Applied Catalysis B: Environmental 267, 118700

Wang Z, Han W, Wang Z, Huang D, Qin H, He Y, Chen M, Zeng G, Xu P (2021): Ferrocene modified g- $\mathrm{C}_{3} \mathrm{~N}_{4}$ as a heterogeneous catalyst for photo-assisted activation of persulfate for the degradation of tetracycline. Colloids and Surfaces A: Physicochemical and Engineering Aspects 626, 127024

Xiang Q, Yu J, Jaroniec M (2012): Synergetic effect of $\mathrm{MoS}_{2}$ and graphene as cocatalysts for enhanced photocatalytic $\mathrm{H}_{2}$ production activity of $\mathrm{TiO}_{2}$ nanoparticles. J Am Chem Soc $134,6575-8$

Xiao J-D, Jiang H-L (2017): Thermally Stable Metal-Organic Framework-Templated Synthesis of Hierarchically Porous Metal Sulfides: Enhanced Photocatalytic Hydrogen Production. Small (Weinheim an der Bergstrasse, Germany) 13

Xiong T, Cen W, Zhang Y, Dong F (2016): Bridging the $\mathrm{g}-\mathrm{C}_{3} \mathrm{~N}_{4}$ Interlayers for Enhanced Photocatalysis. ACS Catalysis 6

Xu P, Chen M, Lai C, Zeng G, Huang D, Wang H, Gong X, Qin L, Liu Y, Mo D, Wen X, Zhou C, Wang R (2019): Effects of typical engineered nanomaterials on 4-nonylphenol degradation in river sediment: based on bacterial community and function analysis. Environmental Science: Nano 6, 2171-2184

Xue X, Chen R, Yan C, Hu Y, Zhang W, Yang S, Ma L, Zhu G, Jin Z (2019): Efficient photocatalytic nitrogen fixation under ambient conditions enabled by the heterojunctions of n-type $\mathrm{Bi}_{2} \mathrm{MoO}_{6}$ and oxygen-vacancyrich p-type BiOBr. Nanoscale 11, 10439-10445 
Yan J, Zhou C, Li P, Chen B, Zhang S, Dong X, Xi F, Liu J (2016): Nitrogen-rich graphitic carbon nitride: Controllable nanosheet-like morphology, enhanced visible light absorption and superior photocatalytic performance. Colloids and Surfaces A: Physicochemical and Engineering Aspects 508, 257-264

Yan S, Li Z, Zou Z (2009a): Photodegradation Performance of $\mathrm{g}-\mathrm{C}_{3} \mathrm{~N}_{4}$ Fabricated by Directly Heating Melamine. Langmuir : the ACS journal of surfaces and colloids 25, 10397-401

Yan S, Li Z, Zou Z (2010): Photodegradation of Rhodamine B and Methyl Orange over Boron-Doped g$\mathrm{C}_{3} \mathrm{~N}_{4}$ under Visible Light Irradiation. Langmuir : the ACS journal of surfaces and colloids 26, 3894-901

Yan SC, Li ZS, Zou ZG (2009b): Photodegradation performance of $\mathrm{g}-\mathrm{C}_{3} \mathrm{~N}_{4}$ fabricated by directly heating melamine. Langmuir 25, 10397-401

Yan W, Yan L, Jing C (2019): Impact of doped metals on urea-derived $g-\mathrm{C}_{3} \mathrm{~N}_{4}$ for photocatalytic degradation of antibiotics: Structure, photoactivity and degradation mechanisms. Applied Catalysis B: Environmental 244, 475-485

Yang S, Gong Y, Zhang J, Zhan L, Ma L, Fang Z, Vajtai R, Wang X, Ajayan PM (2013): Exfoliated Graphitic Carbon Nitride Nanosheets as Efficient Catalysts for Hydrogen Evolution Under Visible Light. Advanced Materials 25, 2452-2456

Yang W, Wang J, Pan T, Xu J, Zhang J, Cao C-n (2002): Studies on the electrochemical characteristics of $\mathrm{K}_{2} \mathrm{Sr}\left(\mathrm{FeO}_{4}\right)_{2}$ electrode. Electrochemistry Communications 4, 710-715

Yu J, Wang S, Low J, Xiao W (2013): Enhanced photocatalytic performance of direct Z-scheme g- $\mathrm{C}_{3} \mathrm{~N}_{4}-$ $\mathrm{TiO}_{2}$ photocatalysts for the decomposition of formaldehyde in air. Physical Chemistry Chemical Physics $15,16883-16890$

Yu Y, Wang J (2015): Direct microwave synthesis of graphitic $\mathrm{C}_{3} \mathrm{~N}_{4}$ with improved visible-light photocatalytic activity. Ceramics International 42

Yu Y, Zhou Q, Wang J (2016): Ultra-rapid synthesis of 2D graphitic carbon nitride nanosheets via direct microwave heating for field emission. Chem. Commun. 52

Yu Y, Wang C, Luo L, Wang J, Meng J (2018): An environment-friendly route to synthesize pyramid-like g$\mathrm{C}_{3} \mathrm{~N}_{4}$ arrays for efficient degradation of rhodamine $\mathrm{B}$ under visible-light irradiation. Chemical Engineering Journal $334,1869-1877$

Yuan J, Liu X, Tang Y, Zeng Y, Wang L, Zhang S, Cai T, Liu Y, Luo S, Pei Y, Liu C (2018): Positioning cyanamide defects in $\mathrm{g}-\mathrm{C}_{3} \mathrm{~N}_{4}$ : Engineering energy levels and active sites for superior photocatalytic hydrogen evolution. Applied Catalysis B: Environmental 237, 24-31 
Yuan Y-p, Yin L, Cao S, Gu L, Xu G, Du P, Chai H, Liao Y, Xue C (2014): Microwave-Assisted Heating Synthesis: A General and Rapid Strategy for Large-Scale Production of High Crystalline g- $\mathrm{C}_{3} \mathrm{~N}_{4}$ with Enhanced Photocatalytic $\mathrm{H}_{2}$ Production. Green Chem. 16

Zhang C, Lu Y, Jiang Q, Hu J (2016a): Synthesis of CdS hollow spheres coupled with g- $\mathrm{C}_{3} \mathrm{~N}_{4}$ as efficient visible-light-driven photocatalysts. Nanotechnology 27, 355402

Zhang C, Lu Y, Jiang Q, Hu J (2016b): Synthesis of CdS hollow spheres coupled with g- $\mathrm{C}_{3} \mathrm{~N}_{4}$ as efficient visible-light-driven photocatalysts. Nanotechnology 27, 355402

Zhang G, Zhang M, Ye X, Qiu X, Lin S, Wang X (2014): lodine Modified Carbon Nitride Semiconductors as Visible Light Photocatalysts for Hydrogen Evolution. Advanced Materials 26, 805-809

Zhang J, Grzelczak M, Hou Y, Maeda K, Domen K, Fu X, Antonietti M, Wang X (2012): Photocatalytic oxidation of water by polymeric carbon nitride nanohybrids made of sustainable elements. Chemical Science 3, 443-446

Zhang K, Wang L, Sheng X, Ma M, Jung MS, Kim W, Lee H, Park JH (2016c): Tunable Bandgap Energy and Promotion of $\mathrm{H}_{2} \mathrm{O}_{2}$ Oxidation for Overall Water Splitting from Carbon Nitride Nanowire Bundles. Advanced Energy Materials 6

Zhang L, Xia Z (2011): Mechanisms of Oxygen Reduction Reaction on Nitrogen-Doped Graphene for Fuel Cells. The Journal of Physical Chemistry C 115

Zhang X, Jing D, Guo L (2010): Effects of anions on the photocatalytic $\mathrm{H}_{2}$ production performance of hydrothermally synthesized Ni-doped $\mathrm{Cd}_{0.1} \mathrm{Zn}_{0.9} \mathrm{~S}$ photocatalysts. International Journal of Hydrogen Energy 35, 7051-7057

Zhao Y, Zhao F, Wang X, Xu C, Zhang Z, Shi G, Qu L (2014): Graphitic Carbon Nitride Nanoribbons: Graphene-Assisted Formation and Synergic Function for Highly Efficient Hydrogen Evolution.

Angewandte Chemie International Edition 53, 13934-13939

Zhou W, Li W, Wang J-Q, Qu Y, Yang Y, Xie Y, Zhang K, Wang L, Fu H, Zhao D (2014): Ordered Mesoporous Black $\mathrm{TiO}_{2}$ as Highly Efficient Hydrogen Evolution Photocatalyst. Journal of the American Chemical Society 136

Zhou X, Jin B, Chen R, Peng F, Fang Y (2013): Synthesis of porous $\mathrm{Fe}_{3} \mathrm{O}_{4} / \mathrm{g}-\mathrm{C}_{3} \mathrm{~N}_{4}$ nanospheres as highly efficient and recyclable photocatalysts. Mater. Res. Bull. 48, 1447-1452

Zhu J, Diao T, Wang W, Xu X, Sun X, Carabineiro SAC, Zhao Z (2017): Boron doped graphitic carbon nitride with acid-base duality for cycloaddition of carbon dioxide to epoxide under solvent-free condition. Applied Catalysis B: Environmental 219, 92-100 
Zhu Y-P, Ren T-Z, Yuan Z-Y (2015): Mesoporous Phosphorus-Doped g- $\mathrm{C}_{3} \mathrm{~N}_{4}$ Nanostructured Flowers with Superior Photocatalytic Hydrogen Evolution Performance. ACS Applied Materials \& Interfaces 7, 1685016856

Zou J, Yu Y, Yan W, Meng J, Zhang S, Wang J (2019): A facile route to synthesize boron-doped g- $\mathrm{C}_{3} \mathrm{~N}_{4}$ nanosheets with enhanced visible-light photocatalytic activity. Journal of Materials Science 54

\section{Figures}
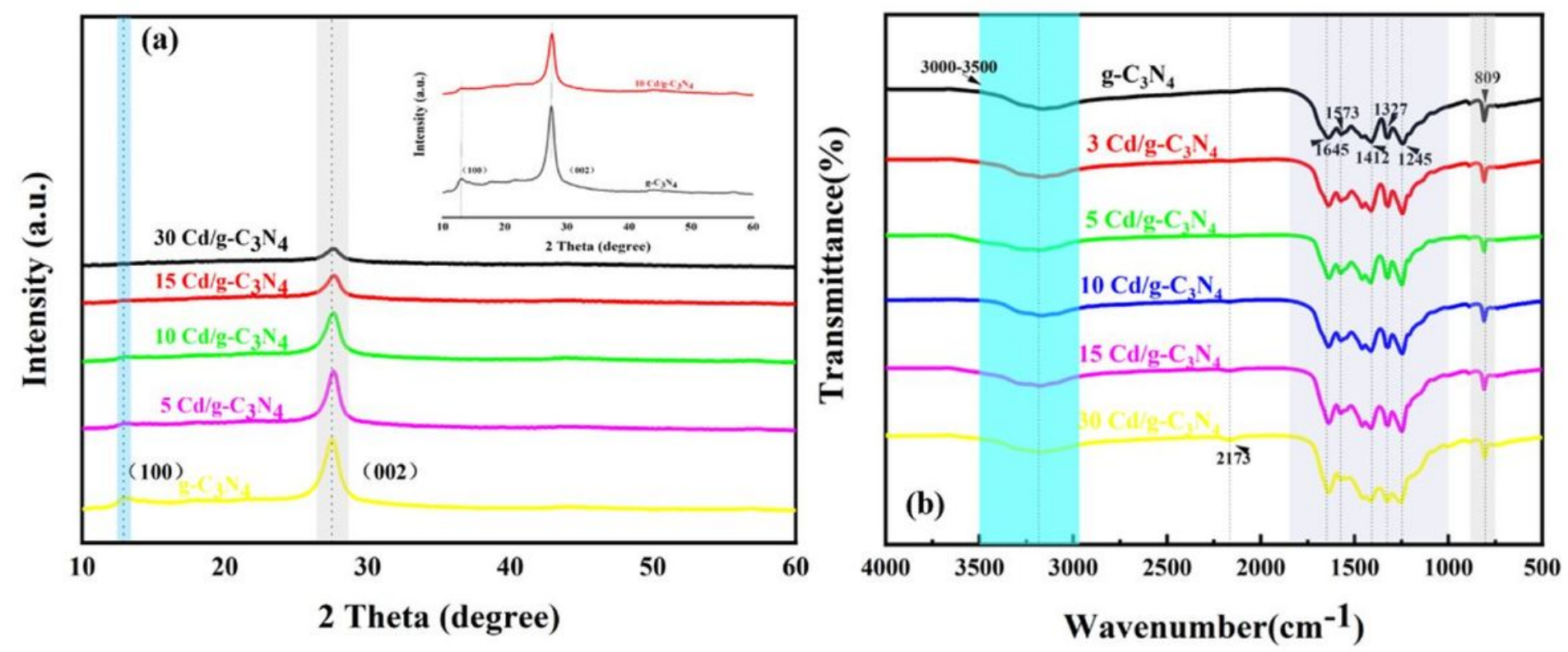

Figure 1

(a) XRD patterns of pure g-C3N4 and Cd/g-C3N4 composites; (b) FT-IR spectra of pure g-C3N4 and Cd/gC3N4 composites. 

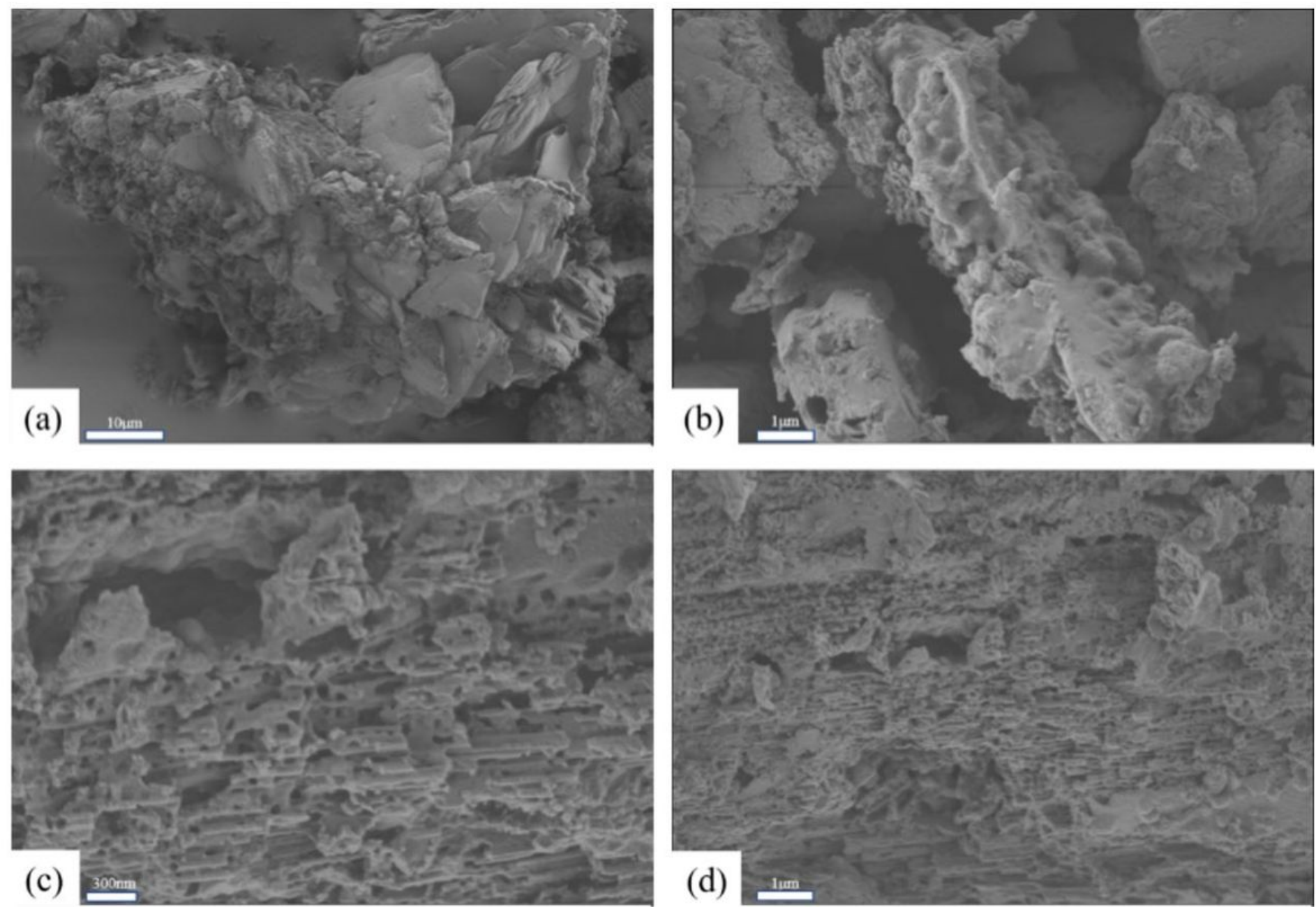

Figure 2

SEM images of g-C3N4 (a-b) and $10 \mathrm{Cd} / \mathrm{g}-\mathrm{C} 3 \mathrm{~N} 4(\mathrm{c}-\mathrm{d})$. 

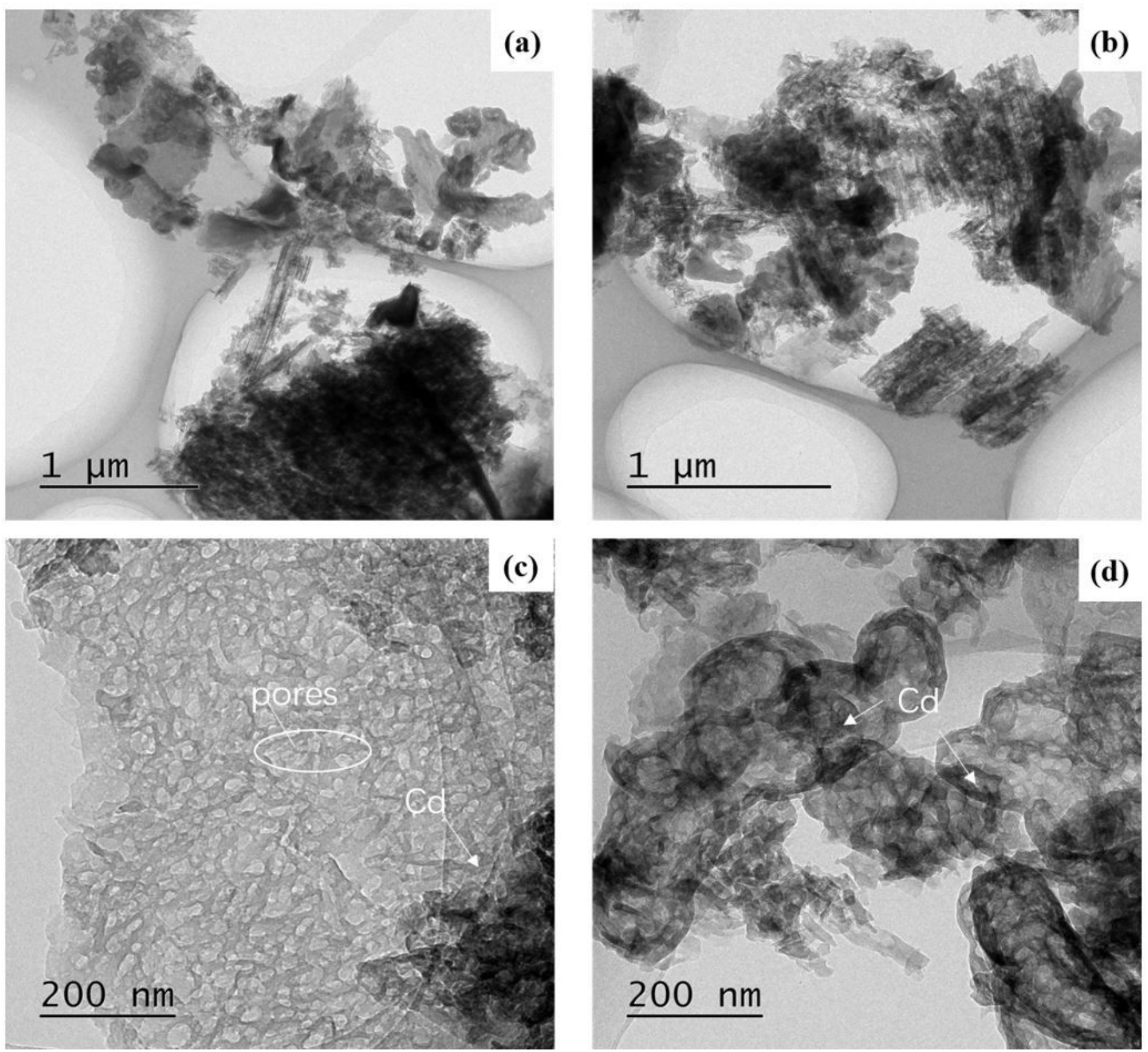

\section{Figure 3}

TEM images of g-C3N4 (a-b) and $10 \mathrm{Cd} / \mathrm{g}-\mathrm{C} 3 \mathrm{~N} 4(\mathrm{c}-\mathrm{d})$. 

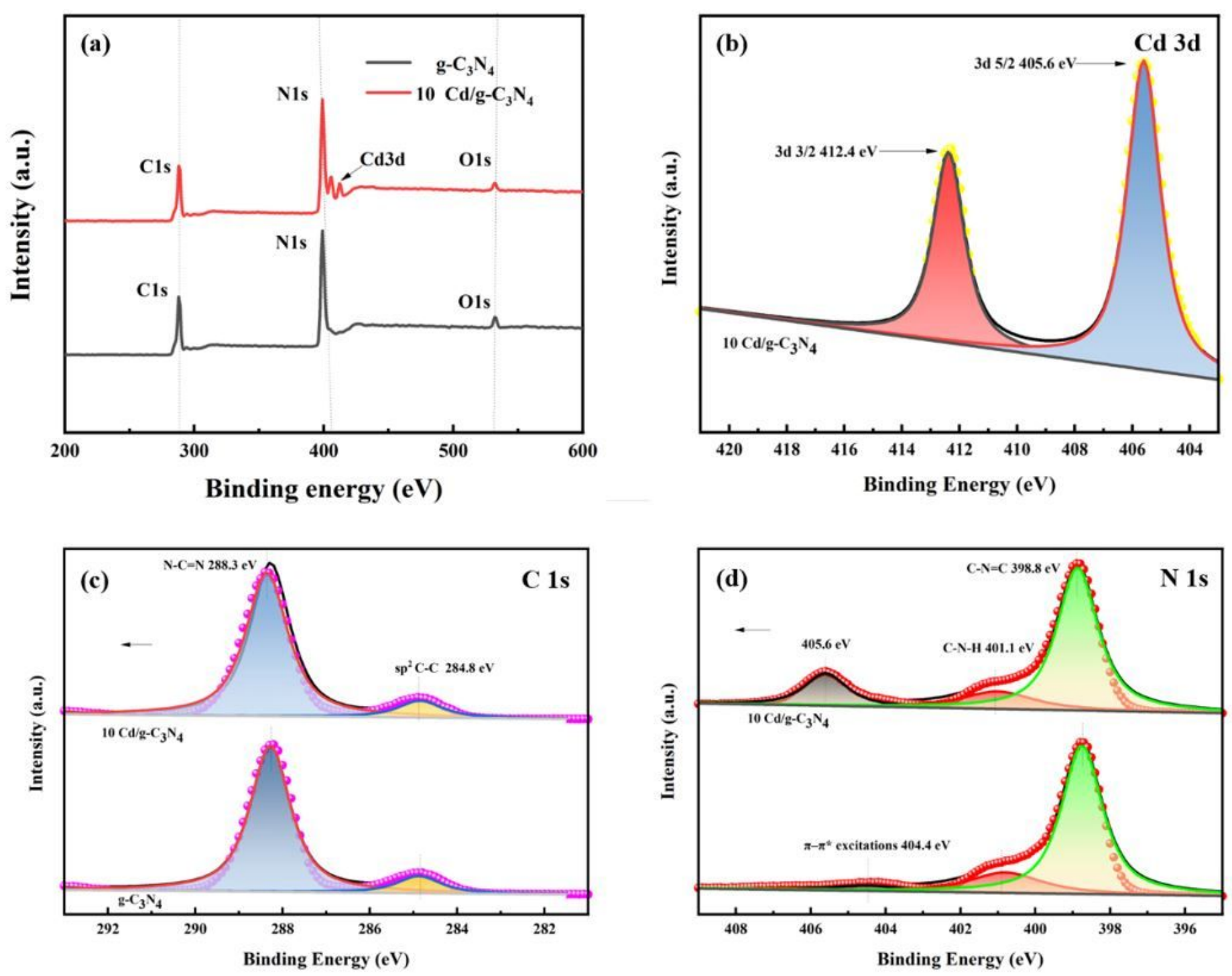

Figure 4

XPS spectra of pure g-C3N4 and $10 \mathrm{Cd} / \mathrm{g}$-C3N4. (a) full survey spectrum, (b) high-resolution Cd 3d, (c) high-resolution $\mathrm{C} 1 \mathrm{~s}$, (d) high-resolution N 1s. 

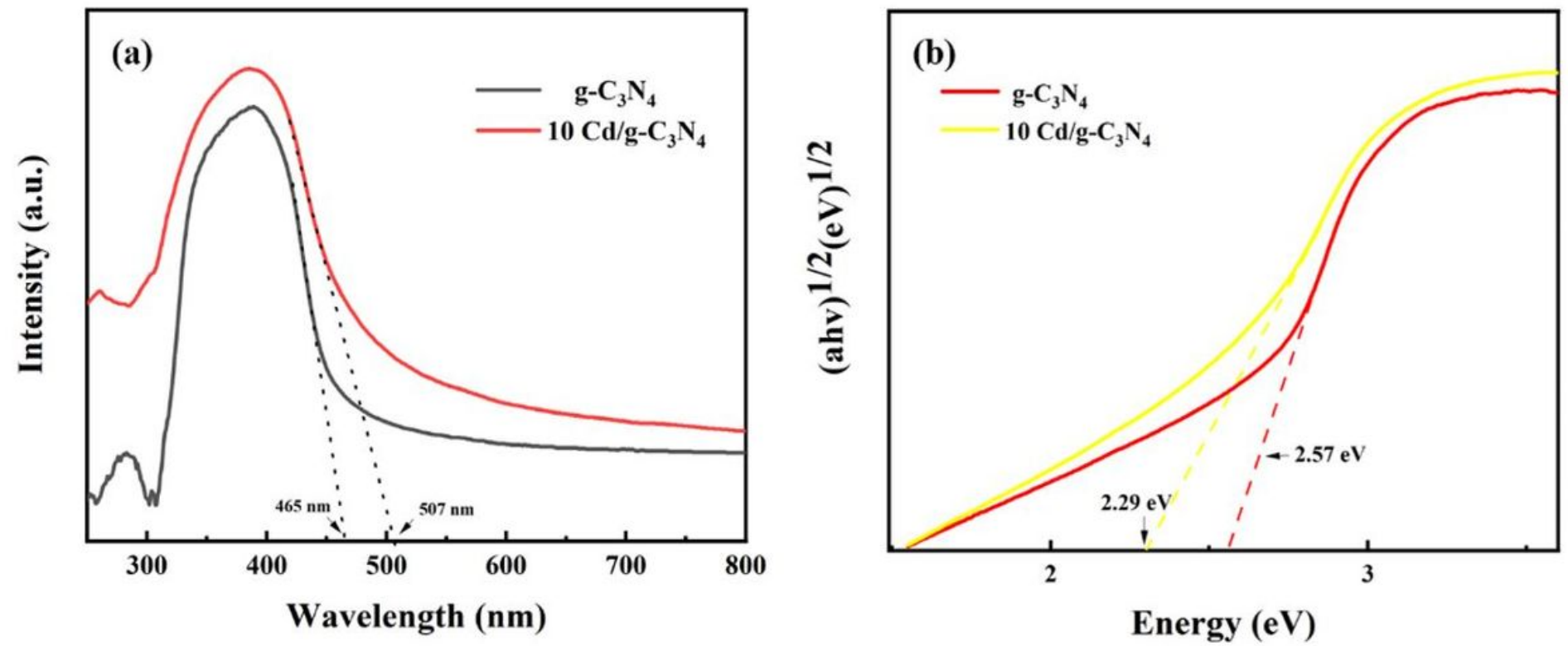

Figure 5

(a) UV-vis diffuse reflectance spectra (DRS) and (b) band gap of g-C3N4 and $10 \mathrm{Cd} / \mathrm{g}$-C3N4 composites. 

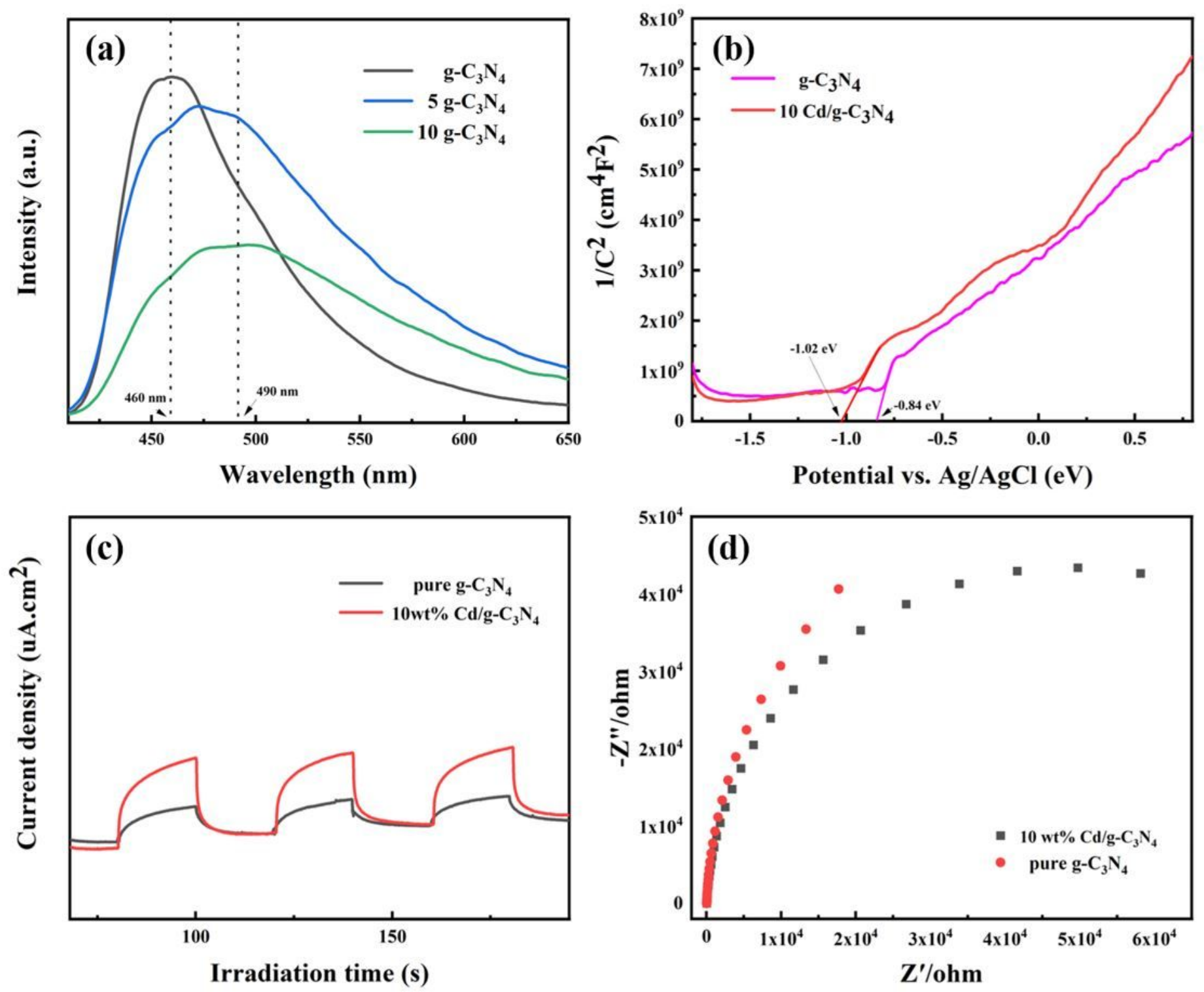

Figure 6

(a) The PL spectra and (b) Mott-Schottky plots of pure g-C3N4 and Cd/g-C3N4 composites. (c) Photocurrent response spectra and (d) EIS Nyquist plots of pure g-C3N4 and $10 \mathrm{Cd} / \mathrm{g}-\mathrm{C} 3 \mathrm{~N} 4$ composite. 

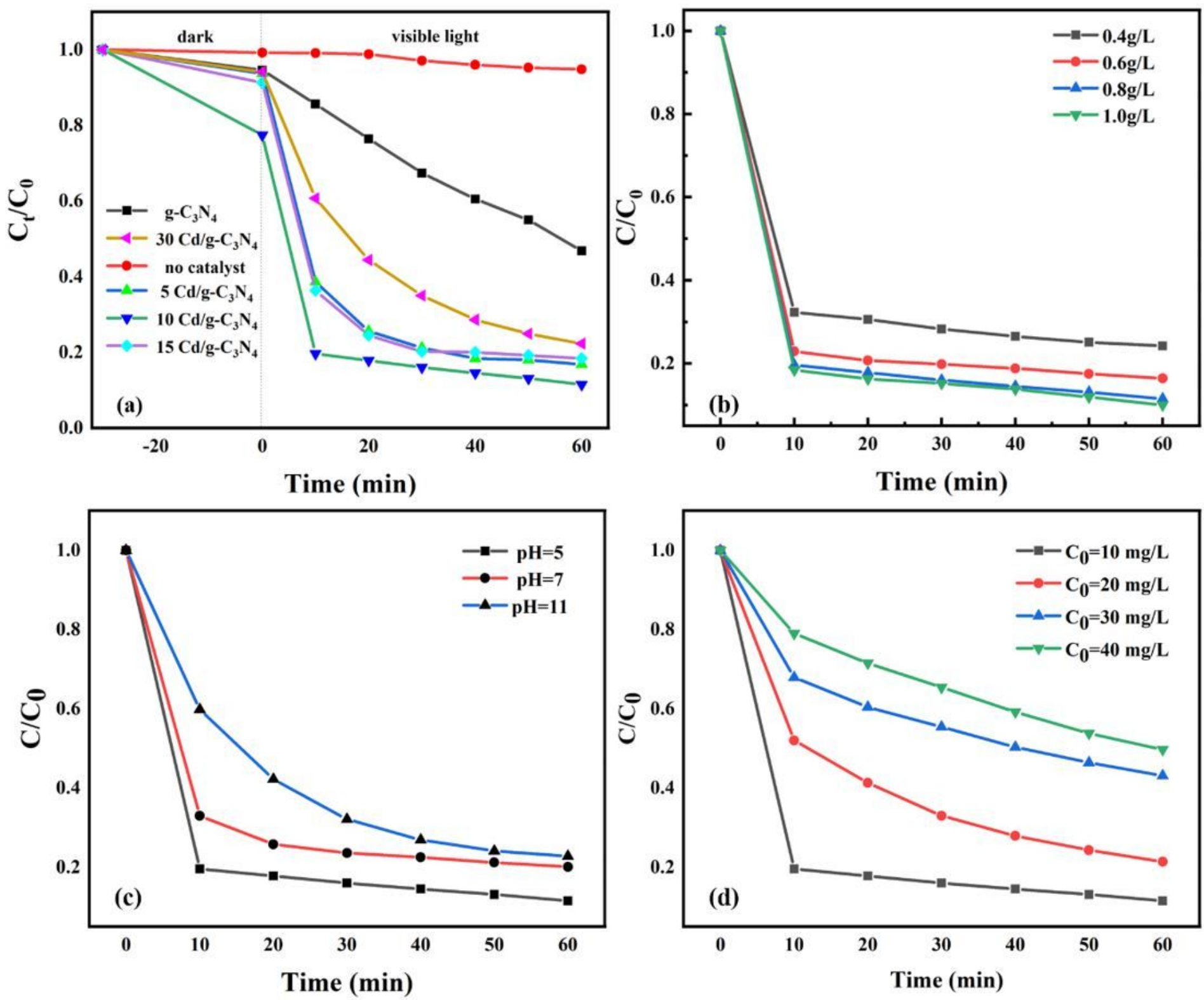

Figure 7

(a) Degradation performance of catalysts curves with different amounts cadmium. Experimental conditions: [Cd/g-C3N4]0 $=0.8 \mathrm{~g} \mathrm{~L}-1$, [TC]0 $=20 \mathrm{mg} \mathrm{L}-1$, and T $=25 \circ \mathrm{C}$. (b) Degradation efficiency of different catalyst dosages. Experimental conditions: $[T C] 0=20 \mathrm{mg} \mathrm{L}-1$, and $\mathrm{T}=25 \circ \mathrm{C}$. (c) Degradation efficiency of $\mathrm{Cd} / \mathrm{g}-\mathrm{C} 3 \mathrm{~N} 4$ composites with different $\mathrm{pH}$. Experimental conditions: [Cd/g-C3N4]0 $=0.8 \mathrm{~g}$ $\mathrm{L}-1,[\mathrm{TC}] 0=20 \mathrm{mg} \mathrm{L}-1$, and $\mathrm{T}=25 \circ \mathrm{C}$. (d) Degradation efficiency of catalyst with different initial TC concentrations. Experimental conditions: $[\mathrm{Cd} / \mathrm{g}-\mathrm{C} 3 \mathrm{~N} 4] 0=0.8 \mathrm{~g} \mathrm{~L}-1$, and $\mathrm{T}=25 \circ \mathrm{C}$. 

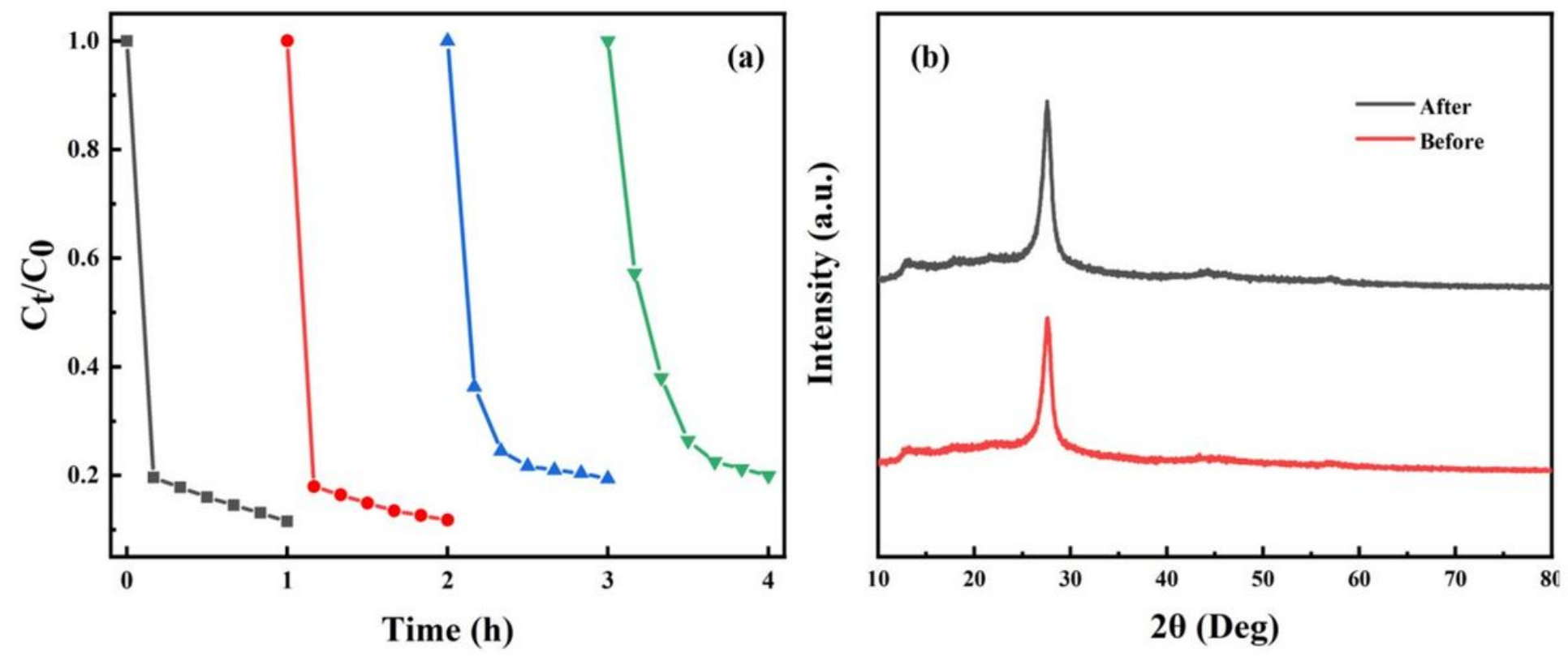

Figure 8

(a) Degradation efficiency of TC over $10 \mathrm{Cd} / \mathrm{g}$-C3N4 composite under four cycling tests. (b) XRD images of $10 \mathrm{Cd} / \mathrm{g}-\mathrm{C} 3 \mathrm{~N} 4$ before and after four times used. 

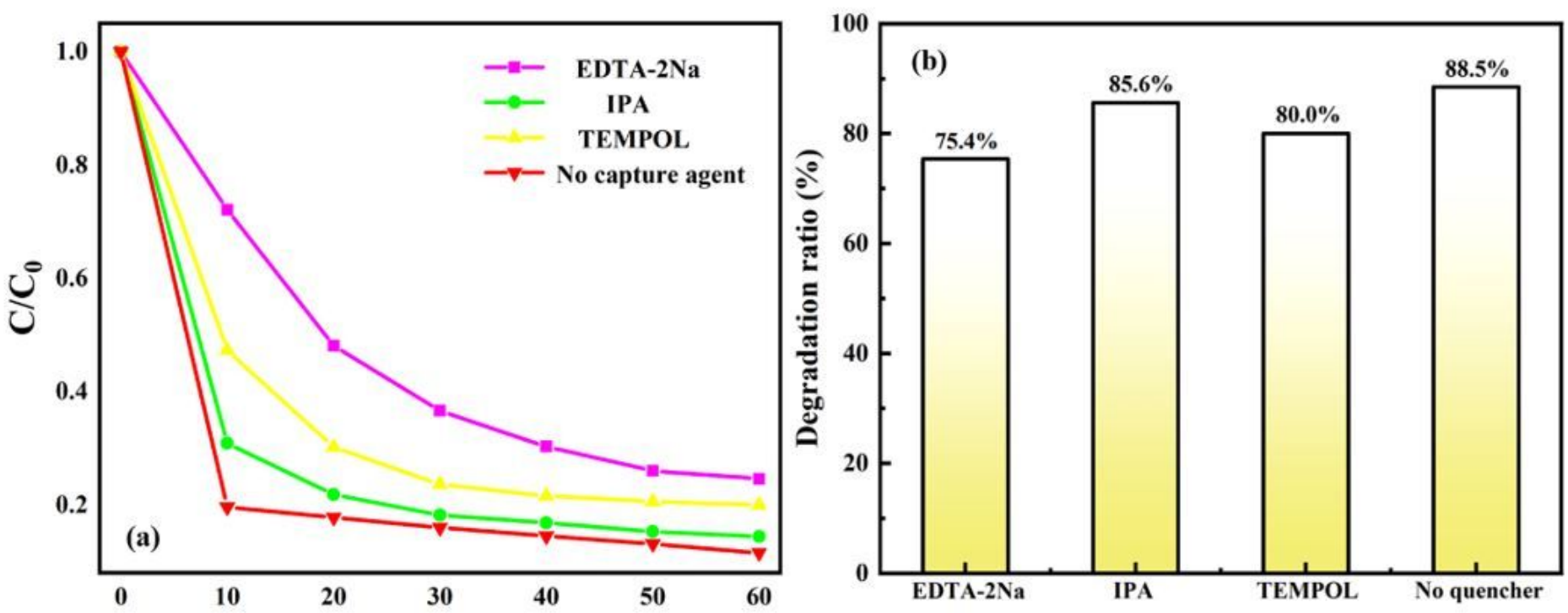

Time (min)
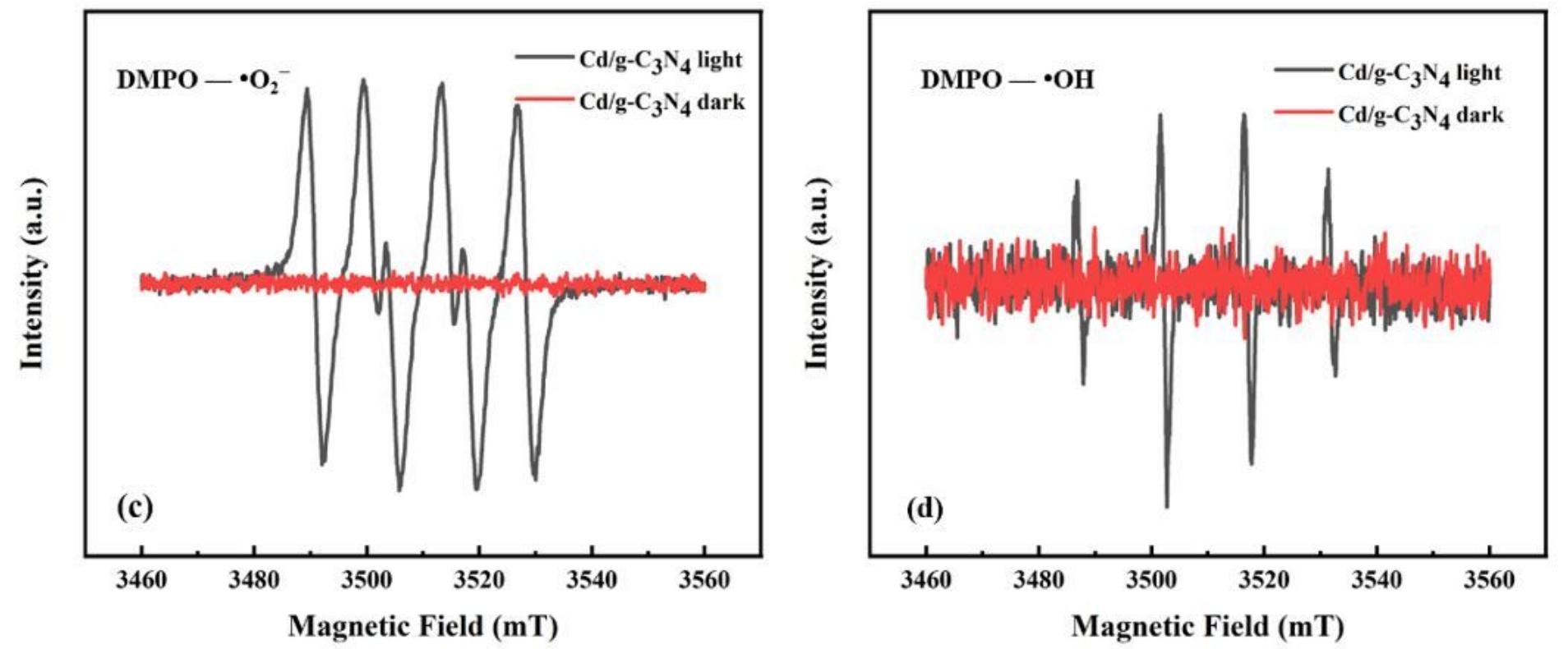

Figure 9

(a-b) Degradation efficiency of $10 \mathrm{Cd} / \mathrm{g}$-C3N4 under different quenchers. ESR spectra for (c) DMPO$\cdot 02-$ and (d) DMPO- $\cdot \mathrm{OH}$ under dark and visible light condition.

\section{Supplementary Files}

This is a list of supplementary files associated with this preprint. Click to download.

- Table.docx

- SupplementsFile.docx 